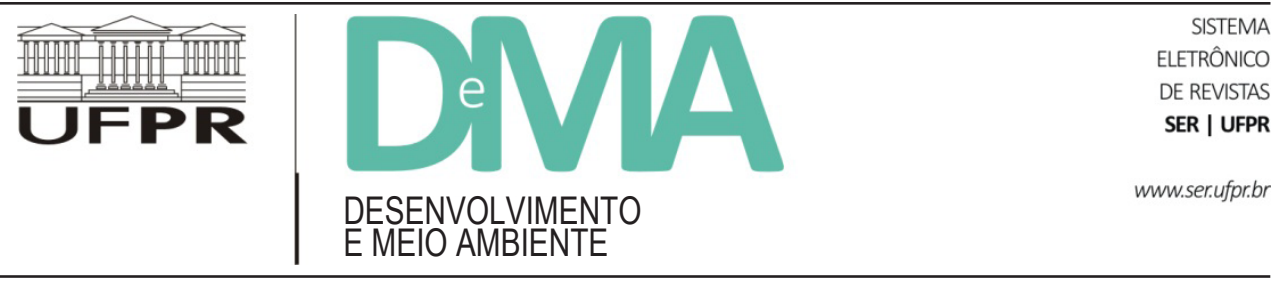

\title{
Comportamentos e perceções acerca da participação pública em ciência e tecnologia e nas alterações climáticas: os casos de Portugal e Espanha
}

\section{Practices and Perceptions About Public Participation in Science and Technology and in Climate Change: The Cases of Portugal and Spain}

\author{
Liliana OLIVEIRA $^{1 *}$, Anabela CARVALHO ${ }^{1}$ \\ ${ }^{1}$ Universidade do Minho, Braga, Portugal. \\ *E-mail de contato: liliana.ua@gmail.com
}

Artigo recebido em 30 de outubro de 2016, versão final aceita em 23 de dezembro de 2016.

RESUMO: A urgência de um maior envolvimento público nos debates e nos processos de tomada de decisão relacionado com as alterações climáticas tem vindo a ser crescentemente apontada em vários relatórios (eg. IPCC, 2007; 2013; 2014a; 2014b) e por diversos autores (eg. Caride \& Meira, 2004; O’Neill \& Nicholson-Cole, 2009; Lakoff, 2010; Phillips et al., 2012). No entanto, a participação dos cidadãos portugueses e espanhóis na questão tem sido promovida fundamentalmente através de iniciativas de participação não dialógicas, resumindo-se a sua atuação fundamentalmente a ações de poupança energética e à reciclagem. A partir da administração de um inquérito exploratório a 227 cidadãos portugueses e espanhóis, são analisados os comportamentos, as perceções e os constrangimentos à sua participação nas alterações climáticas, identificando-se os principais fatores que podem influenciar o seu envolvimento nos debates e processos decisórios e analisando a importância que atribuem à sua participação nas decisões que envolvem temas científicos. Os dados obtidos denotam alguma preocupação e bastante interesse na questão das alterações climáticas por parte dos cidadãos inquiridos em ambos os países, com destaque para os seus efeitos, e a maioria referiu sentir-se razoavelmente informada acerca destes temas. Os cidadãos inquiridos consideram que a consulta pública sobre temas de C\&T ainda não é suficiente, assumindo na sua grande maioria que não tem estado ativamente envolvidos em tais processos. Reconhecem, igualmente, que têm um papel pouco participativo nestas questões, em particular nas alterações climáticas, apontando como constrangimentos relevantes a sua iliteracia científica e o desinteresse que os cidadãos no geral têm por temas de cariz científico, a resistência demonstrada pelos decisores à democratização deste tipo de debates e à implementação de instrumentos participativos, o difícil acesso à informação e as dificuldades de comunicação entre os cientistas e os cidadãos.

Palavras-chave: participação pública; "public engagement with Science"; comunicação de ciência; alterações climáticas. 
ABSTRACT: An increasingly number of reports (eg. IPCC, 2007, 2013, 2014a, IPCC, 2014b) and scholars (eg. Caride \& Meira, 2004; O'Neill \& Nicholson-Cole, 2009; Lakoff, 2010; Phillips et al., 2012) have called attention to the urgency of deepening public engagement in debates and decision-making processes on climate change. However, the participation of Portuguese and Spanish citizens on the issue has been basically fulfilled through non-dialogical initiatives and their action is often limited to energy saving behaviours and recycling. Based on an exploratory survey study with 227 Portuguese and Spanish citizens, the article analyses behaviours, perceptions and constraints related to participation in climate change. The main factors that influence citizens' engagement in debates and decision-making processes are identified, and the importance that they award to participation in decisions that involve science-related matters is analised. Data suggest some concern and a good degree of interest in climate change, and especially its effects, by citizens in both countries. The majority of respondents stated that they felt reasonably well-informed about these themes. Inquired citizens consider that public consultation on science and technology issues is insufficient, although the majority states that they have not been actively involved in such processes. They also recognize that they have little participation in these matters, in particular climate change, and point out, as relevant constraints, their scientific illiteracy and lack of interest for scientific issues, the resistance displayed by decision-makers to democratizing these kinds of debates and implementing participatory mechanisms, the difficulty in accessing information and difficulties in the communication between scientists and citizens.

Keywords: public participation; public engagement with science; science communication; climate change.

\section{Introdução}

As alterações climáticas ${ }^{1}$ são uma problemática que implica vários conflitos entre interesses coletivos e individuais, bem como entre perspetivas científicas, políticas e sociais. Sendo um tema de grande complexidade, tem-se demonstrado um dilema social em termos normativos e práticos e um "problema perverso" (Lorenzoni et al., 2007; Irwin, 2009; Raihani \& Aitken, 2011; Capstick, 2013).

Tratando-se de um problema ambiental multidimensional, de longo prazo e com um caráter global, as alterações climáticas são "particularmente difíceis de entender e se relacionar a um nível individual" (Ockwell et al., 2009, p. 310). Implica "múltiplas escalas temporais e espaciais", e diferentes "valores éticos, sociais e culturais" nas decisões relacionadas com a sua mitigação e adapta- ção, requerendo uma "ação concertada" (Carvalho, 2008a, p. 8) com um claro desequilíbrio na partilha da responsabilidade. Meira Cartea (2008) considera-as um "processo sinérgico" que resulta "numa "situação complexa" onde o científico e o sociopolítico estão em constante interação e tensão" (p. 81). Dadas estas características, torna-se manifesto que as alterações climáticas colocam significativos desafios cognitivos, psicológicos, políticos e sociais a um qualquer envolvimento sustentável do público e à adoção generalizada de novos comportamentos e de atitudes que beneficiem o reequilíbrio do clima (Owens, 2000; Lorenzoni et al., 2007; Emmert et al., 2010).

A urgência de um maior envolvimento público no debate e no processo de tomada de decisão relacionado com as alterações climáticas tem vindo a ser intensificada em vários relatórios (eg. IPCC,

\footnotetext{
${ }^{1}$ Baseamo-nos no conceito de alterações climáticas adotado pela Convenção Quadro das Nações Unidas para a Mudança do Clima: mudança no clima "atribuída direta ou indiretamente à atividade humana, que altera a composição da atmosfera global e que é, para além de variabilidade climática natural, observada ao longo de períodos comparáveis" (<http://unfccc.int/files/documentation/text/html/list_search.php?\%20 zwhat $=$ keywords\&val $=\&$ valan $=$ a\&anf $=0 \& i d=10>$ ).
} 
2007; 2013; 2014a; 2014b) e proclamada por diversos autores (eg. Caride \& Meira, 2004; O’Neill \& Nicholson-Cole, 2009; Lakoff, 2010; Phillips et al., 2012). Uma comunicação que promova uma participação pública adaptada ao contexto social e cultural dos cidadãos, e que tenha em consideração os processos psicossociais e culturais que influenciam as suas representações sociais, as suas perceções e os aspetos cognitivos, afetivos e ideológicos que lhe estão associados, adquire aqui, portanto, uma importância significativa, e poderá desempenhar um papel fundamental na forma como a sociedade enfrenta a questão e as mudanças que têm de ser feitas. O envolvimento público em questões climáticas tem, como mostra Carr et al. (2013, p. 575), a potencialidade de tornar as decisões ética, política, social e tecnologicamente mais legítimas e robustas, ao "incorporar os pontos de vista e as preocupações dos diversos públicos" que são afetados por essas decisões.

Este modelo "cívico" é, porém, um desafio, exigindo que "as pessoas tenham a capacidade de agir como cidadãos informados no momento em que os componentes cruciais interligados desse processo - conhecimento, capacidade e cidadania - estão sujeitos a interpretação crítica e renegociação" (Owens, 2000, p. 1145). A reformulação dos processos participativos não parece ser suficiente, considerando que muitas pessoas tornaram-se consumidores "alienados como cidadãos" (p. 1146). O conjunto de significados sociais e culturais que guiam as perceções e ações são mediados por um conjunto de práticas sociais e discursivas e é na interação dessas práticas, de estruturas institucionais e processos comunicativos que se desenvolve a nossa forma de agir (Doyle, 2011).

Torna-se necessário, portanto, perceber como é que se podem mobilizar os cidadãos, considerando que essa mobilização muito depende da forma como os mesmos se comportam e das escolhas que fazem, dos seus contextos sociais e das estruturas governamentais e institucionais disponíveis para promover esse envolvimento. Ainda que haja já uma significativa produção de conhecimento em torno das atitudes dos indivíduos em relação às alterações climáticas, parece de significativa importância realizar mais estudos sobre a forma como os indivíduos percecionam e agem em relação às alterações climáticas, como interpretam a sua ação individual neste contexto e que recursos têm para efetivar essa ação. Por outro lado, será, também, relevante perceber a influência de diversos agentes num envolvimento mais efetivo dos cidadãos, tendo em consideração que só através de "um trabalho mais sustentado que examine a diversidade de ambientes organizacionais nos quais a ciência é realizada [...] podemos compreender o modo pelo qual diferentes racionalidades institucionais emergem, persistem, e dão aso à cidadania científica" (Bickerstaff et al., 2010, p. 494).

Com esse propósito, este artigo incide em particular nas perceções dos cidadãos portugueses e espanhóis em relação à importância da sua participação na questão e nos fatores que influenciam o seu envolvimento nas alterações climáticas.

\section{Contexto}

Vários estudos mostram que, em Portugal e em Espanha, a responsabilidade pelas decisões que as alterações climáticas requerem é predominantemente atribuída pelos cidadãos a terceiros, como o governo, a União Europeia e a indústria. Apesar de se mostrarem preocupados com a questão, a sua atuação resume-se fundamentalmente a ações de poupança energética e à reciclagem, assumindo uma desresponsabilização individual (Schmidt \& Nave, 
2003; Domínguez Arcos et al., 2011; Meira Cartea et al., 2009; Meira Cartea et al., 2011, 2013; European Commission, 2011a; 2011b; 2014a; Lázaro et al., 2011; Schmidt et al., 2011; Carvalho et al., 2014; Schmidt \& Delicado, 2014).

Em Portugal, a opinião pública ainda raramente está presente na definição da agenda política ambiental e os escassos mecanismos participativos existentes não geram uma discussão relevante, funcionando muitas vezes como mera formalidade para a aprovação de projetos (Carvalho \& Gupta, 2012). Os decisores políticos têm desvalorizado o envolvimento com os parceiros sociais e com o público (Carvalho et al., 2014), propiciando poucas oportunidades para o público se envolver na questão, construindo-a de forma predominantemente tecno-gestionária, com a tónica principal em medidas regulatórias (Carvalho, 2011a). Os portugueses são dos europeus que menos identificam as alterações climáticas como principal problema da humanidade e que mais mal informados se sentem acerca dessas alterações, apresentando um nível de conhecimento baixo sobre o tema (Dunlap, 1998; Schmidt \& Nave, 2003; Delicado \& Gonçalves, 2007; Cabecinhas et al., 2011; Carvalho, 2011b; Carvalho et al., 2014; Delicado et al., 2011; European Commission, 2011a; 2011b; 2014a; Lázaro et al., 2011; Schmidt et al., 2011).

Em Espanha, nos últimos anos, a administração pública central tem procurado desenvolver alguns mecanismos que potenciem a participação pública (Yábar Sterling, 2006). No entanto, essa participação tem sido praticamente restringida aos parceiros sociais do setor económico, passando, ainda, muitas vezes, pela implementação de ações de consulta e de sensibilização cidadã num formato não dialógico. Ainda que o nível de consciencialização dos espanhóis tenha vindo a melhorar ao longo dos anos (Jori García, 2009)2 ${ }^{2}$, individualmente a participação dos cidadãos continua a ser limitada (Todt, 1999) e a sua preocupação não se tem traduzido em ações concretas. Com a crise financeira o tema tem vindo a perder alguma importância (Meira Cartea et al., 2011; 2013; Rodriguez-Priego et al., 2012; Alonso et al., 2014; European Commission, 2014a). A maioria afirma-se disponível para alterar comportamentos, mas resiste a participar em medidas que signifiquem um esforço a nível pessoal (CIS, 2007; Fundación BBVA, 2008; Oltra et al., 2008; Meira Cartea et al., 2009; Meira Cartea et al., 2011; Domínguez Arcos et al., 2011; AXA, 2013; Solaun et al., 2014). Ainda que o nível de conhecimentos no geral seja razoável, a maioria ainda se sente mal informada (Fundación BBVA, 2008; Oltra et al., 2008; Meira Cartea et al., 2009; Meira Cartea et al., 2011; 2013).

É importante perceber, por isso, quais são os fatores que podem explicar esta falta de interesse revelado pelos cidadãos quando se trata de participar. A partir da análise dos dados apurados com a realização de um inquérito exploratório a 227 cidadãos portugueses e espanhóis, são analisados os comportamentos, as perceções e os constrangimentos à sua participação nas alterações climáticas, identificando-se os principais fatores que podem influenciar o envolvimento destas comunidades na discussão da temática e percebendo a importância que atribuem à sua participação nas decisões que envolvem temas científicos, de que são exemplo as alterações climáticas.

\footnotetext{
2 São dos europeus mais preocupados com a questão (AXA, 2013; European Commission, 2011b, 2014a) percecionando-o como um dos principais problemas ambientais do país e como uma das maiores ameaças do planeta (Domínguez Arcos et al., 2011; European Commission, 2011b; Meira Cartea et al., 2009; Oltra et al., 2008).
} 
A análise foi organizada em dois eixos temáticos, de acordo com os objetivos estabelecidos, os fatores em análise e as categorias que resultaram da análise dos dados. São eles: I. Perceções dos cidadãos acerca das alterações climáticas (impressões acerca das alterações climáticas, nível de interesse, nível de informação auto percecionado, fontes de informação e formas de atuação e motivações); II. Posicionamentos em relação ao envolvimento nas alterações climáticas (benefícios percebidos e constrangimentos enfrentados no seu envolvimento).

O conceito de "envolvimento/participação pública" adotado na análise destes dados é bastante abrangente. Seguindo Phillips et al. (2012), assume-se que o envolvimento dos cidadãos implica um diálogo entre os atores sociais e a participação ativa dos cidadãos na definição de problemas, na produção do conhecimento, no debate acerca das suas implicações ou no processo de tomada de decisões relacionadas com estes temas. Implica o acesso ao processo de produção de conhecimento e/ou ao processo decisório, uma aprendizagem mútua, uma interação dialógica entre os vários atores e a integração dos vários tipos de saberes nesses processos.

\section{O estudo}

Administrado presencialmente a 227 pessoas (115 em Portugal e 112 em Espanha), a duas amostras diversificadas e estratificadas em diversas variáveis sociodemográficas (cidadãos indiscriminados e participantes de iniciativas de divulgação científica), o inquérito serviu nesta investigação para explorar as representações, crenças e informações fatuais que os cidadãos tinham sobre eles próprios e sobre o seu envolvimento e participação pública em questões relacionadas com $\mathrm{C} \& \mathrm{~T}$ de que podem ser exemplo as alterações climáticas.
Estabeleceram-se como objetivos deste questionário perceber o tipo de perceção que os cidadãos têm em relação às alterações climáticas, o seu grau de envolvimento e participação nesta temática e os seus posicionamentos em relação à importância da consulta pública em questões relacionadas com C\&T. Foram, portanto, fatores de análise a) a perceção pública das alterações climáticas (nível de interesse; nível de informação; fontes de informação) [Carvalho, 2008b; Hulme, 2009; Lakoff, 2010; Moser, 2010; Doyle, 2011; Carvalho \& Peterson, 2012] e b) a perceção pública acerca da participação pública em temas de C\&T (potencialidades e barreiras à participação pública) [European Institute for Public Participation, 2009; European Commission, 2012; 2013; 2014b].

Partindo dos objetivos específicos traçados, foi definida como população do questionário a sociedade portuguesa e espanhola e como amostra um grupo constituído por pessoas recrutadas num espaço público de grande circulação e em iniciativas de divulgação científica.

Os inquiridos foram selecionados através de uma amostragem acidental, tendo o questionário sido entregue pessoalmente aos cidadãos, em Portugal e em Espanha, entre novembro de 2012 e Outubro de 2013. Foram distribuídos 300 questionários ao todo, tendo sido recolhidos 115 questionários em Aveiro (Portugal) e 112 questionários em Salamanca e Valladolid (Espanha), com uma percentagem bastante satisfatória de taxa de retorno $(88,4 \% \mathrm{em}$ Portugal e 65,8\% em Espanha).

Construído a partir de perguntas abertas e fechadas, com um tempo de resposta previsto de 15 minutos, nas línguas dos cidadãos visados, o inquérito tem um caráter não probabilístico. Não tendo havido grandes preocupações na constituição de uma amostra representativa, reúne, no entanto, dados respeitantes a pessoas com diferentes perfis, 
conferindo-lhe alguma solidez enquanto estudo exploratório.

$\mathrm{Na}$ análise dos dados obtidos foi aplicada uma análise de conteúdo temática nas respostas de pergunta aberta e uma análise quantitativa dos dados nas respostas de pergunta fechada com recurso ao programa Microsoft - EXCEL 2010 e o software IBM SPSS Statistics, versão 20.0 (Pereira, 2006; Martins, 2011). Os dados foram analisados através de um processo de "vaivém entre teoria e dados", articulando "o tratamento quantitativo com as observações de ordem qualitativa que contextualizam a informação" (Ferreira, 2001, p. 193). A partir de um conjunto de questões formuladas para analisar os resultados obtidos com o questionário, foram realizadas análises descritivas, para descrever e interpretar a forma como os sujeitos percecionam as alterações climáticas e a importância do seu envolvimento no debate e tomada de decisões sobre estas temáticas. Foram também realizadas análises correlacionais para explorar e identificar a existência de pontos em comum e diferenças entre portugueses e espanhóis.

Em Portugal, os 115 indivíduos inquiridos têm idades compreendidas entre os 17 e os 77 $\operatorname{anos}(\mathrm{M}=43,19 ; \mathrm{DP}=12.121 ; \mathrm{Mo}=32), 69(60,5 \%)$ do sexo feminino e 45 (39,5\%) do sexo masculino $(\mathrm{DP}=0.491, \mathrm{NR}=1)$. A sua maioria possui habilitações literárias ao nível do ensino superior $(62,6 \%)$ e do ensino secundário $(20 \%)(\mathrm{DP}=1.125)$, e profissões como especialistas de profissões intelectuais e científicas $(40,7 \%)$ e técnicos e profissionais de nível intermédio (17,7\%). Em Espanha, os 112 indivíduos têm idades compreendidas entre os $18 \mathrm{e}$ os 71 $\operatorname{anos}(\mathrm{M}=39,41 ; \mathrm{DP}=12.041 ; \mathrm{Mo}=43), 55(49,1 \%)$ do sexo feminino e $57(50,9 \%)$ do sexo masculino $(\mathrm{DP}=0.502)$. A sua maioria possui formação superior $(61,6 \%)$ e ao nível do ensino secundário $(17,9 \%)(\mathrm{DP}=1.002)$, e profissões como especialistas de profissões intelectuais e científicas $(44,4 \%)$.

De seguida são analisadas as perceções dos inquiridos em relação às alterações climáticas, o seu grau de interesse e de informação, as fontes de informação que procuram para se informarem acerca do tema e as formas de contacto que mantêm com a questão. São, ainda, analisadas as suas perceções e o seu posicionamento em relação à sua participação em temas de C\&T, que importância atribuem à sua participação, que benefícios identificam nesse envolvimento e os principais constrangimentos que têm impedido a sua participação mais ativa neste tipo de temáticas.

\section{Perceções dos cidadãos acerca das alterações climáticas}

\subsection{Impressões sobre alterações climáticas}

Numa associação livre de ideias ao tema das alterações climáticas, que era parte integrante do questionário, a maioria dos termos citados em Portugal foram sinónimos de alterações climáticas, e termos associados aos seus efeitos (ex: "catástrofes naturais", "alterações nas estações do ano", "subida do nível do mar", "degelo", "extinção de espécies", "esgotamento de recursos"). Em Espanha, alguns termos repetiram-se, tendo-se evidenciado, contudo, uma associação frequente a outros termos que denotam uma visão bastante negativista da problemática (ex: "contaminação" (sinónimo de poluição em Espanha), "problemas", "destruição", "seca", "desertificação" e "extinção"). 
Esta primeira análise à representação visual dos termos com recurso ao "wordle" é confirmada numa análise mais pormenorizada baseada na categorização dos termos (Figura 1). Essa categorização mostra, efetivamente, que entre as 306 referências portuguesas e as 283 espanholas, as ideias mais citadas em ambos os países relacionam-se com os efeitos das alterações climáticas.

Em Portugal, os inquiridos associaram, também, às alterações climáticas ideias ligadas às causas percebidas, com especial destaque para as causas antropogénicas $^{3}$ (ex: “desaparecimento da camada

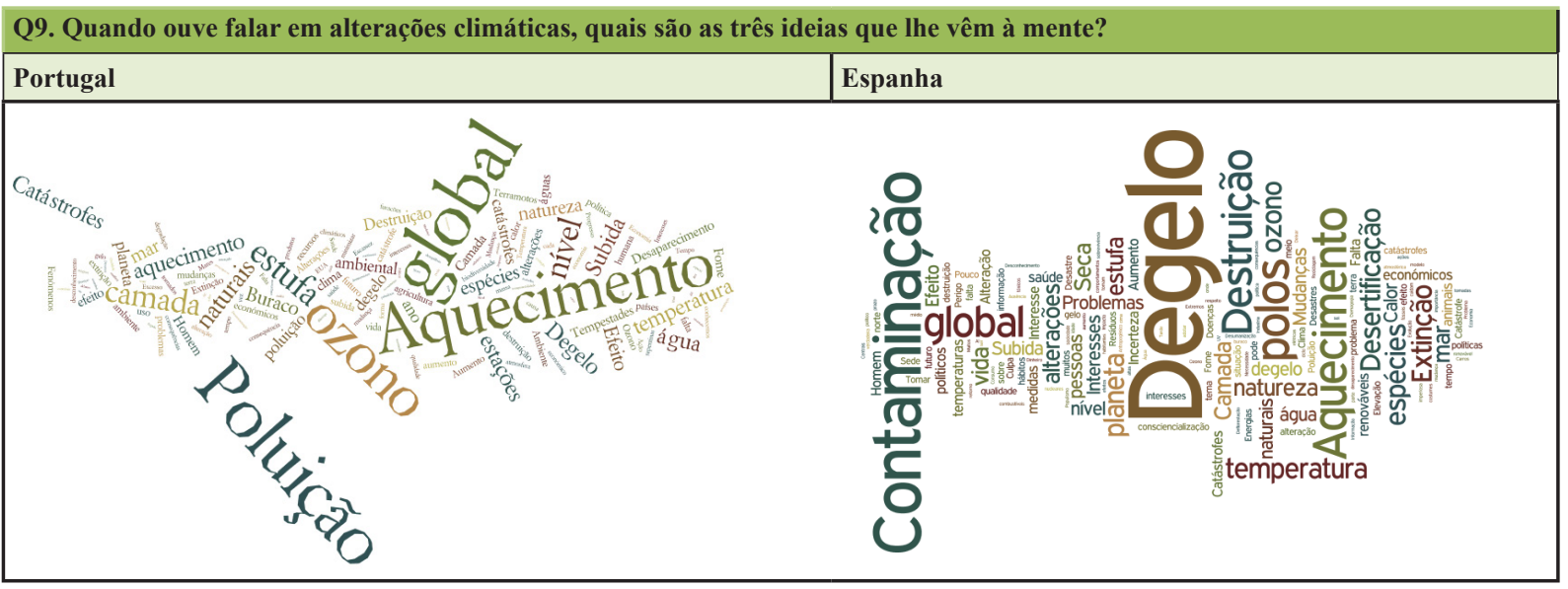

\section{Q9. Quando ouve falar em alterações climáticas, quais são as três ideias que lhe vêm à mente?}

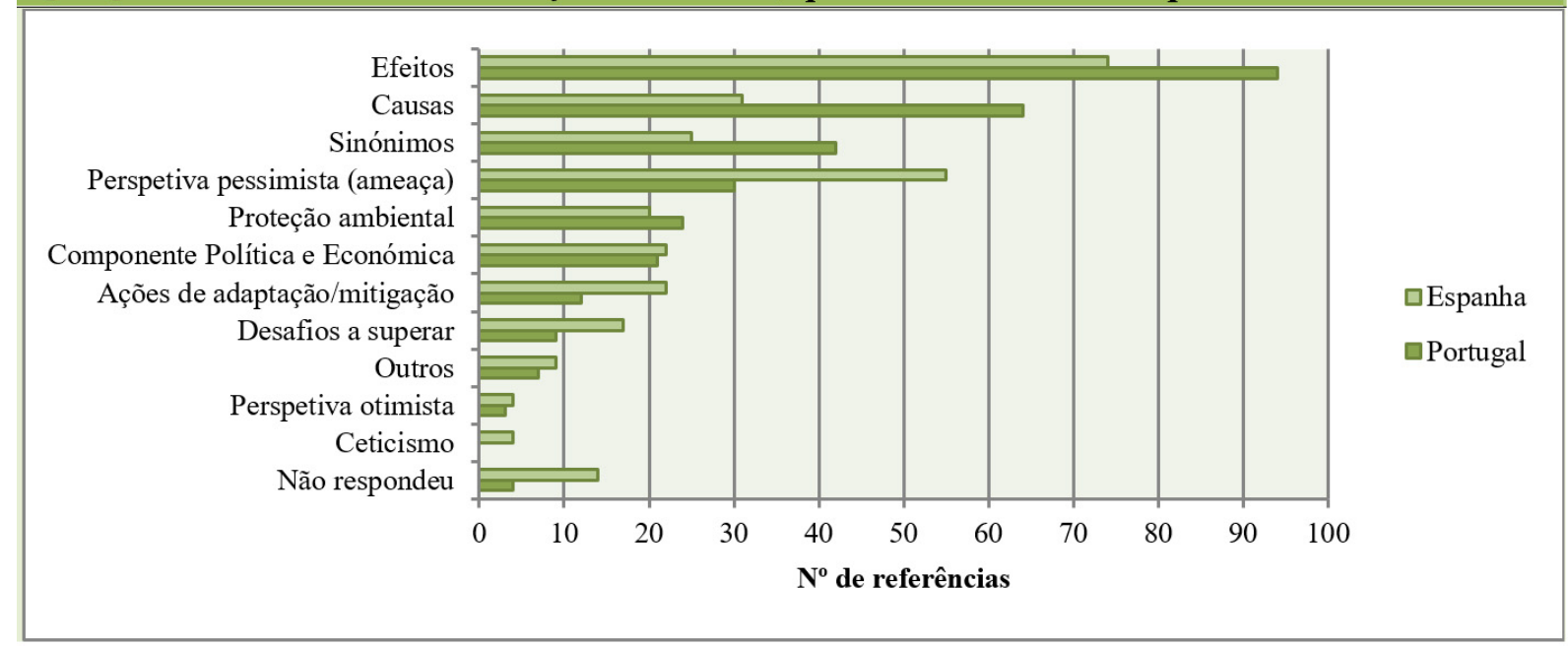

FIGURA 1 - Ideias associadas às alterações climáticas.

${ }^{3}$ Nesta classificação foram consideradas as classificações dos impactos adotadas pelo IPCC (http://www.ipcc.ch/) e pela UNFCCC (http://unfccc. int/2860.php) [Causas naturais: ciclo solar, variação orbital, impacto de meteoritos, deriva de continentes, fenómeno "el niño", arrefecimento global e glaciações "Idade do gelo", vulcanismo; Causas antropogénicas: emissão de gases com efeito estufa, desmatamento, queima de combustíveis fósseis, cultivo de gado, uso exaustivo do automóvel, utilização de sprays com aerossóis, ar condicionado, buraco na camada de ozono] 
do ozono", "efeito estufa", "Homem como principal causa", "falta de civismo dos cidadãos em relação à natureza"), a sinónimos (ex: "mudanças repentinas da atmosfera", "mudança do clima", "aquecimento da terra") e a alguns aspetos ligados ao ambiente (ex: "pegada ambiental", "degradação do planeta", "chuvas ácidas"). Em Espanha, para além dos impactos das alterações climáticas, destacaram-se as referências ligadas a uma perspetiva mais dramática da temática (ex: "ponto de não retorno", "morte", "consequências graves e irrecuperáveis na vida e na natureza", "destruição", "inevitável”, "tarde para evitá-las", "involução", "pobreza”, "incerteza para o futuro", "catástrofe"). Importa referir que as únicas quatro referências conotadas com uma posição cética/negacionista também foram enunciadas por espanhóis (Ex: "incerteza nos efeitos das alterações com os modelos de predição atuais", "incerteza no impacto real da ação nas alterações", "fraude", "demagogia"). Foram mencionados, igualmente, com alguma frequência, termos relacionados com as causas das alterações climáticas e alguns sinónimos.

Estes dados confirmam de alguma maneira os resultados avançados em alguns estudos já realizados em Portugal (Carvalho, 2011b) e em Espanha (Meira Cartea et al., 2013). Também esses estudos mostraram que os impactos das alterações climáticas parecem estar mais salientes nas perceções dos indivíduos, associando na maioria das vezes as alterações climáticas a imagens negativas e catastrofistas, e entendendo-as como uma ameaça. Mantém-se, também, muito presente alguma confusão relativamente às suas causas, associando repetidamente outras questões ambientais e ecológicas, como a "poluição" (termo muito vago que assume múltiplas formas) ou o buraco do ozono, às alterações climáticas.

\subsection{Nivel de interesse nas alterações climáticas}

Estudos realizados sobre Portugal (Almeida, 2000; 2004; Schmidt \& Nave, 2003; Delicado \& Gonçalves, 2007; Carvalho, 2011b; Schmidt et al., 2011) indicam que os cidadãos portugueses têm vindo a mostrar-se mais interessados no assunto ao longo dos anos, não sendo ainda, no entanto, dos europeus mais preocupados com o problema (Schmidt \& Nave, 2003; Delicado \& Gonçalves, 2007; Cabecinhas et al., 2011; Carvalho, 2011b; Delicado et al., 2011; Lázaro et al., 2011; Schmidt et al., 2011; European Commission, 2011a; 2011b; 2014a; Carvalho et al., 2014). Os espanhóis, ao contrário dos portugueses, são dos europeus mais preocupados com a questão (European Commission, 2011b; 2014a; AXA, 2013), tendo mostrado uma tendência bastante positiva no seu nível de consciencialização ao longo dos anos (Jori García, 2009), e percecionando as alterações climáticas, atualmente, como um dos principais problemas ambientais do país e como uma das maiores ameaças do planeta (Fundación BBVA, 2008; Oltra et al., 2008; Domínguez Arcos et al., 2011; European Commission, 2011b; Meira Cartea et al., 2009; Meira Cartea et al., 2009; 2011; 2013).

No entanto, os dados obtidos com o inquérito desenvolvido neste estudo mostram dois países muito idênticos em termos de interesse pelo tema. Apesar do ambiente estar entre os temas que mais interesse despertam nos inquiridos, as alterações climáticas foram posicionadas pouco acima do meio da tabela. Ainda assim, as alterações climáticas têm muito interesse para a maioria dos inquiridos (Figura 2). 


\section{Q1. Indique, por favor, que interesse têm para si os seguintes temas? [Alterações climáticas]}

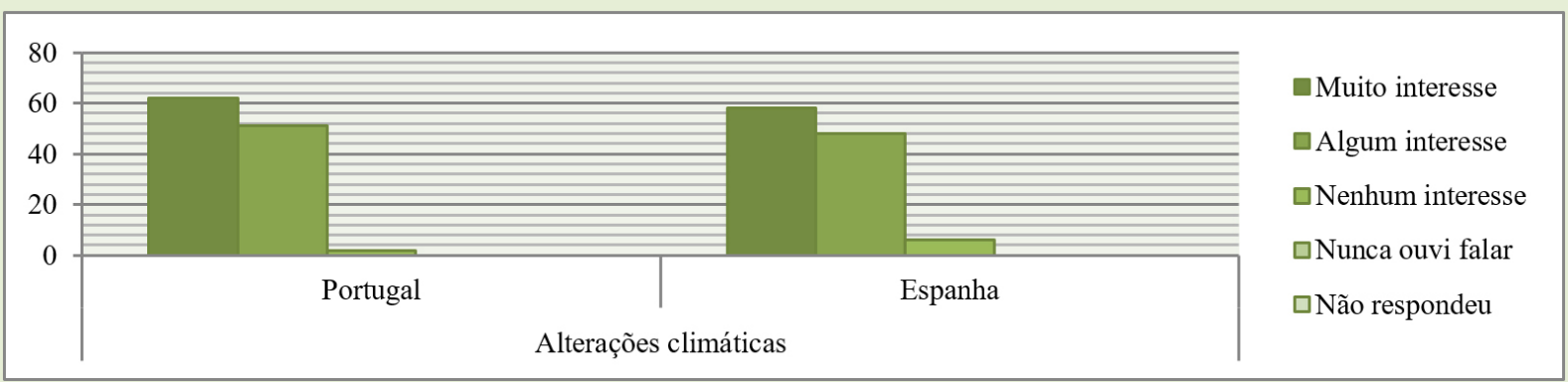

FIGURA 2 - Grau de interesse nas alterações climáticas.

Numa pergunta de resposta fechada, o inquérito permitiu perceber que as causas e os impactos é o tipo de informação que mais interessa aos inquiridos, havendo especial interesse ainda nas ações que podem minimizar essas alterações (Figura 3).

De uma forma geral, os portugueses mostraram mais interesse do que os espanhóis por todas estas questões, com os espanhóis a mostrarem-se relativamente divididos quanto ao seu interesse no esclarecimento das incertezas associadas às causas. Estes dados denotam um interesse maior em adquirir conhecimento sobre a problemática, as suas causas e os seus efeitos, do que sobre formas de ação para a sua mitigação e adaptação, espelhando, de alguma forma, o que já alguns estudos haviam mostrado anteriormente (Carvalho, 2011b; Meira Cartea et al., 2013). Os cidadãos veem as alterações climáticas como uma potencial ameaça, justificando, portanto, o seu grande interesse em perceber os seus impactos, sendo também o tipo de informação que está mais cognitivamente saliente nas perceções dos indivíduos. Isto pode denunciar um posicionamento de "afetado" ou "vítima" face à problemática, acompanhado de um escasso interesse em envolver-se como ator interventivo na procura de soluções.

\section{Q11. Que aspetos relacionados com as alterações climáticas lhe suscitam mais interesse?}

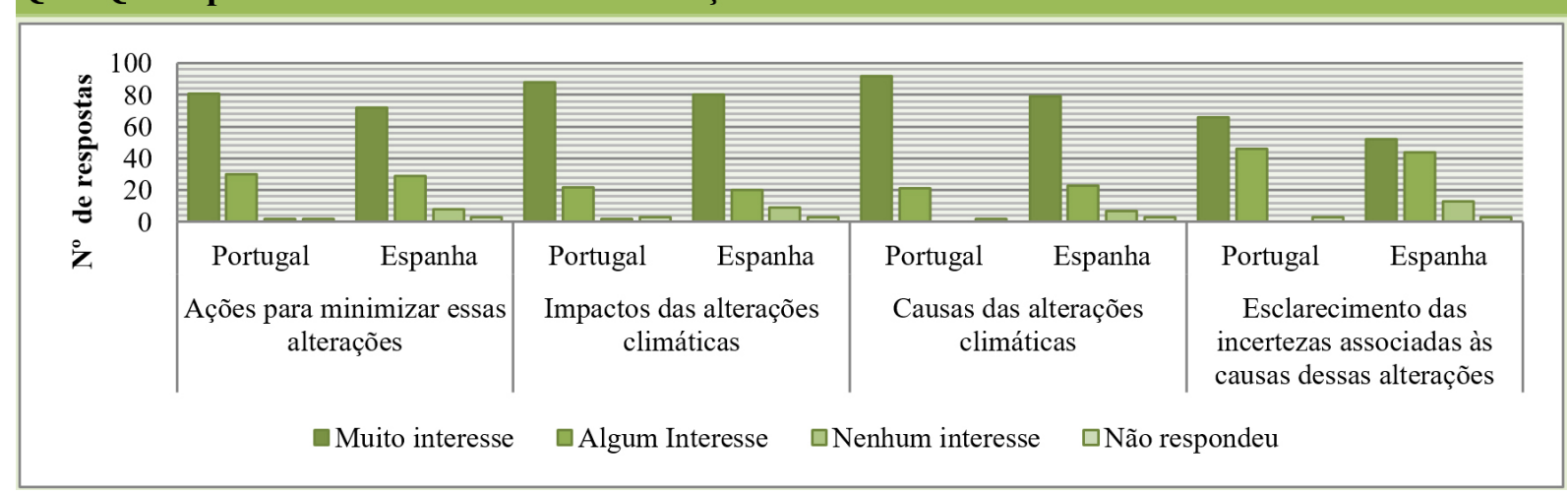

FIGURA 3 - Grau de interesse dos aspetos relacionados com as alterações climáticas. 


\subsection{Nível de informação auto percecionado}

Relativamente ao nível de informação que os cidadãos consideram ter em relação ao tema, alguns estudos têm vindo a mostrar que a maioria dos cidadãos portugueses e espanhóis sentem-se ainda mal informados (Fundación BBVA, 2008; Oltra et al., 2008; Cabecinhas et al., 2011; Carvalho, 2011b; Delicado et al., 2011; Lázaro et al., 2011; Schmidt et al., 2011; European Commission, 2011a; 2011b; 2014a; Meira Cartea et al., 2009; Meira Cartea et al., 2009; 2011; 2013; Carvalho et al., 2014). Porém, os dados do inquérito mostram que, não sendo um dos temas em que se sentem mais informados, as alterações climáticas surgem entre os cinco temas em que os portugueses se sentem muito bem ou bem informados e entre os dez apontados pelos espanhóis (Figura 4). Em ambos os países, a maioria referiu sentir-se razoavelmente informada.

Através de uma análise estatística que relaciona o interesse pelas alterações climáticas e o nível de informação declarado pelos cidadãos (Figura 5) verifica-se que existe uma correlação positiva $(\mathrm{r}=.215)$ entre ambas as variáveis, embora não seja muito expressiva. Em geral, os portugueses, mesmo sem interesse pela questão, sentem-se ligeiramente mais informados sobre a temática do que os espanhóis.
Comparando os tipos de públicos, verifica-se que o público mais interessado nas alterações climáticas é aquele que se sente mais informado.

\subsection{Fontes de informação}

Pouco ativos na procura de informação, os cidadãos de ambos os países utilizam na maioria das vezes os media (televisão, jornais) como principal fonte de informação sobre alterações climáticas (Lázaro et al., 2001; Carvalho, 2011a, Cartea et al., 2009; 2011; 2013).

No inquérito administrado foi pedido aos portugueses e aos espanhóis através de uma pergunta de resposta aberta que indicassem as suas fontes de informação relativamente ao tema das alterações climáticas (Figura 6). As fontes mais consultadas são semelhantes em ambos os países, notando, no entanto, que os portugueses de uma maneira geral consultam uma maior variedade de fontes.

A comunicação social (incluindo, televisão, jornais, revistas e a rádio), a internet, os livros e as revistas científicas são as fontes preferenciais da maioria dos espanhóis e dos portugueses. Importa salientar, no entanto, que tratando-se de uma pergunta de resposta aberta, não fica claro que tipo de sites estão incluídos na internet, pelo que pode-

\section{Q2. Quão informado se sente sobre os seguintes temas? [Alterações climáticas]}

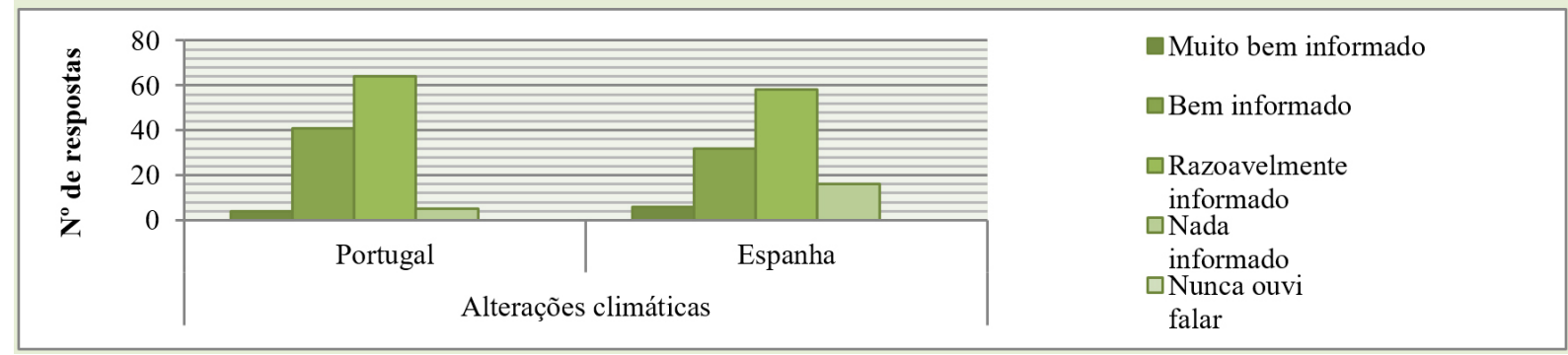

FIGURA 4 - Nível de informação sobre as alterações climáticas detido pelos cidadãos. 


\section{Estatísticas descritivas}

Tabulação cruzada entre nível de interesse pelas alterações climáticas e nível de informação [Portugal e Espanha]

4

Espanha

Muito bem informado

$\square$ Portugal

3
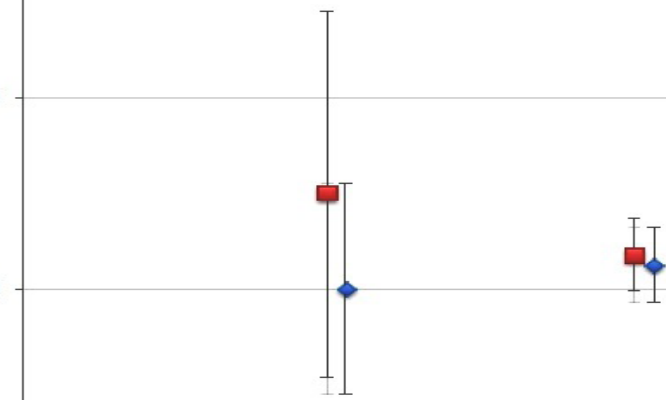

Bem informado

1

Muito interesse

Nada informado

País * Interesse Clima | Variável dependente: InformadoClima

\begin{tabular}{|c|c|c|c|c|}
\hline País & Interesse Clima & Média (Nível de informação)* & Desvio Padrão & $\mathrm{N}$ \\
\hline \multirow{4}{*}{ PT } & Nenhum interesse & 2,50 &, 707 & 2 \\
\hline & Algum interesse & 2,18 &, 596 & 50 \\
\hline & Muito interesse & 2,55 & 619 & 62 \\
\hline & Total & 2,39 & ,631 & 114 \\
\hline \multirow{4}{*}{ ES } & Nenhum interesse & 2,00 & ,632 & 6 \\
\hline & Algum interesse & 2,13 & ,703 & 48 \\
\hline & Muito interesse & 2,38 &, 813 & 58 \\
\hline & Total & 2,25 & ,765 & 112 \\
\hline \multirow{4}{*}{ Total } & Nenhum interesse & 2,13 & ,641 & 8 \\
\hline & Algum interesse & 2,15 & ,648 & 98 \\
\hline & Muito interesse & 2,47 & ,721 & 120 \\
\hline & Total & 2,32 &, 703 & 226 \\
\hline
\end{tabular}

\begin{tabular}{|c|c|c|c|c|c|}
\hline \multirow{2}{*}{ País } & \multirow{2}{*}{ Interesse Clima } & \multirow{2}{*}{ Média (nível de informação)* } & \multirow{2}{*}{$\begin{array}{l}\text { Erro } \\
\text { Padrão }\end{array}$} & \multicolumn{2}{|c|}{ Intervalo de Confiança $95 \%$} \\
\hline & & & & Limite inferior & Limite superior \\
\hline \multirow{3}{*}{ PT } & Nenhum interesse & 2,500 & ,486 & 1,541 & 3,459 \\
\hline & Algum interesse & 2,180 & ,097 & 1,988 & 2,372 \\
\hline & Muito interesse & 2,548 & ,087 & 2,376 & 2,721 \\
\hline \multirow{3}{*}{ ES } & Nenhum interesse & 2,000 & ,281 & 1,446 & 2,554 \\
\hline & Algum interesse & 2,125 & ,099 & 1,929 & 2,321 \\
\hline & Muito interesse & 2,379 & 090 & 2,201 & 2,557 \\
\hline
\end{tabular}

FIGURA 5 - Tabulação cruzada entre nível de interesse pelas alterações climáticas e nível de informação [Portugal e Espanha] *A escala qualitativa foi traduzida em termos quantitativos, correspondendo o 1 a "Nada informado", o 2 a "Razoavelmente Informado", o 3 a "Bem informado" e o 4 a "Muito bem informado". 
mos deduzir que também pode integrar os sites da comunicação social. Talvez, por isso, seja uma das fontes com a posição mais dominante. A televisão lidera os meios de comunicação social consultados, surgindo os jornais em segundo plano e as revistas em terceiro, uma tendência já observada em estudos anteriores realizados nestes países (Carvalho, 2011b; Meira Cartea et al., 2013). O domínio da televisão também pode explicar a associação que grande parte dos inquiridos faz do tema a algum catastrofismo e aos seus efeitos, tendo em conta que este meio tem vindo a dar especial ênfase a essa componente dramática da questão e aos seus impactos (Azevedo et al., 2005; Lorenzoni et al., 2006; Meira Cartea, 2008; Carvalho, 2011b; Meira Cartea et al., 2013).

Os portugueses mostraram dar uma maior prioridade a fontes ligadas diretamente ao campo científico do que os espanhóis, tendo indicado o artigo científico como uma das fontes mais consultadas.
Apesar de serem dos atores sociais que mais confiança inspiram nos cidadãos em questões de C\&T e do ambiente, ao lado dos grupos ecologistas e dos educadores ambientais (Delicado \& Gonçalves, 2007; European Commission, 2010; Muñoz Van den Eynde, 2011; Revuelta, 2011; Meira Cartea et al., 2011; 2013; Bauer \& Howard, 2013; European Commission, 2013), os cientistas não parecem ser, contudo, as fontes de informação científicas mais importantes para os cidadãos ibéricos, sendo preteridos pelas revistas, artigos e organizações científicas.

\section{Posicionamentos em relação ao envolvimento dos cidadãos em temas de C\&T}

Como foi referido anteriormente, os portugueses e os espanhóis estão pouco envolvidos no

\section{Q10. Quais são as fontes de informação que utiliza para se informar sobre as alterações climáticas?}

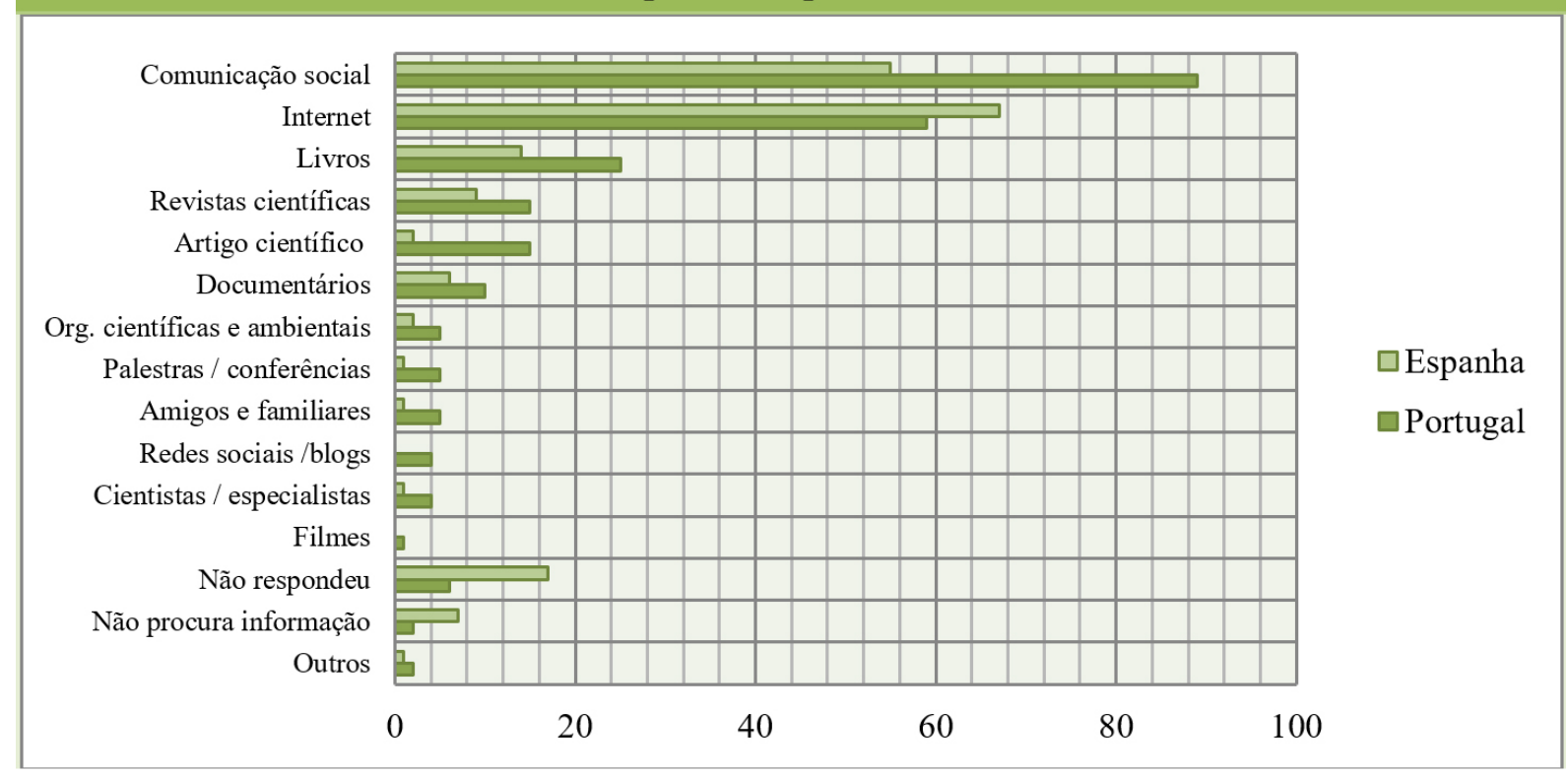

FIGURA 6 - Fontes de informação sobre alterações climáticas. 
debate e nos processos decisórios relacionados com as alterações climáticas, transferindo muitas vezes a responsabilidade da decisão para os decisores políticos, a comunidade científica e as associações ambientalistas e de consumidores (Almeida, 2000; 2004; Delicado \& Gonçalves, 2007; FECYT, 2011; Muñoz Van den Eynde, 2011). Ações organizadas pelos cidadãos ainda são pouco significativas, recorrendo ocasionalmente aos media, aos protestos e às consultas públicas como instrumentos principais para concretizar a sua cidadania e para dar visibilidade às suas posições relacionadas com esta matéria.

\subsection{Benefícios percebidos e limitações normativas do processo}

Apesar dos últimos eurobarómetros ${ }^{4}$ (European Commission, 2010; 2013) terem mostrado que uma percentagem significativa dos portugueses e dos espanhóis reconhecem que a consulta pública é importante e que a sua opinião deve ser levada em conta nas decisões tomadas, cerca de um terço defende, ainda, que os cidadãos devem ter pouca intervenção nas decisões e que as suas opiniões não devem ser vinculativas. No questionário aplicado nesta investigação, uma parte significativa dos inquiridos não expressou uma opinião retumbante quanto à importância do seu próprio envolvimento em consultas públicas sobre ciência (Figura 7).

A maioria denunciou algum ceticismo quanto ao impacto desse envolvimento nas decisões do Governo sobre ciência, tendo sido esse sentimento mais notório entre os inquiridos portugueses. O público espanhol mostrou-se bastante dividido quanto à sua influência no processo decisório.

Contudo, quando a pergunta se torna menos pessoal a grande maioria dos inquiridos concordou que o público não é suficientemente envolvido na tomada de decisões sobre ciência (Figura 8).

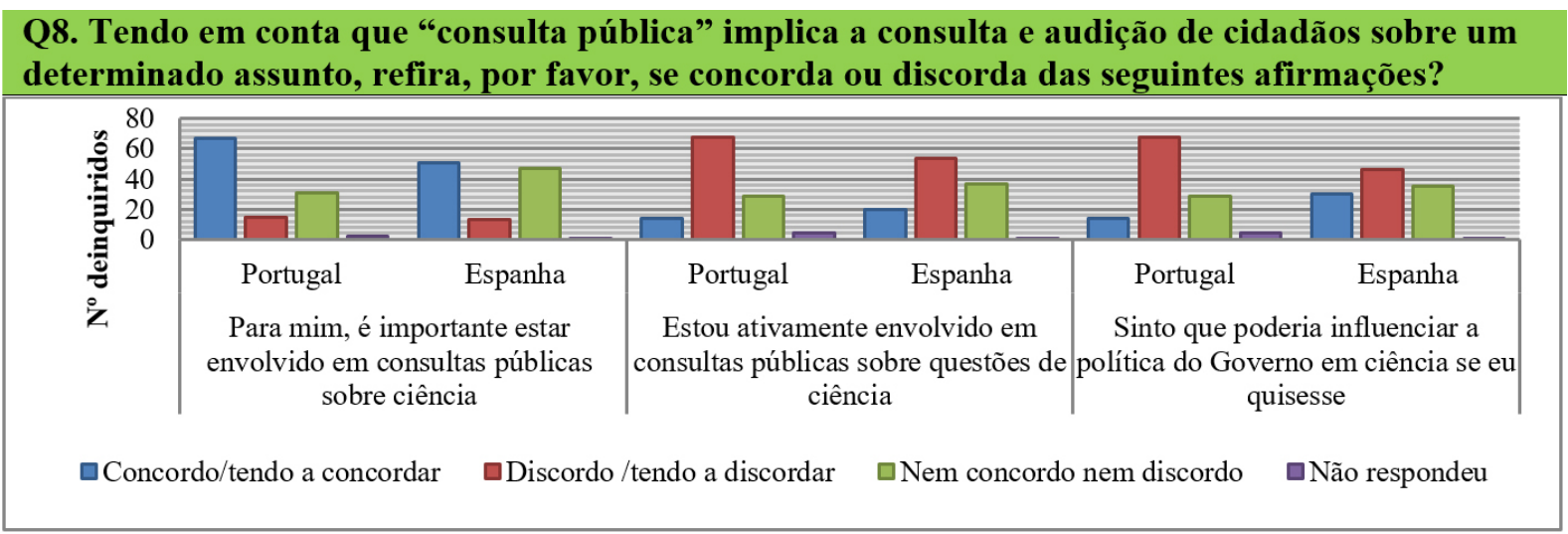

FIGURA 7 - Importância do seu envolvimento em temas de C\&T.

\footnotetext{
${ }^{4}$ Os eurobarómetros são inquéritos que a Comissão Europeia realiza regularmente, já desde 1973, à população com o intuito de analisar e caraterizar a evolução da opinião pública dos seus Estados-Membros sobre diversos temas relacionados com a cidadania europeia, entre os quais o ambiente e a ciência e tecnologia. Os relatórios produzidos a partir dos inquéritos realizados podem ser consultados em http://ec.europa. $\mathrm{eu} / \mathrm{COMMFrontOffice/publicopinion/index.cfm}$
} 


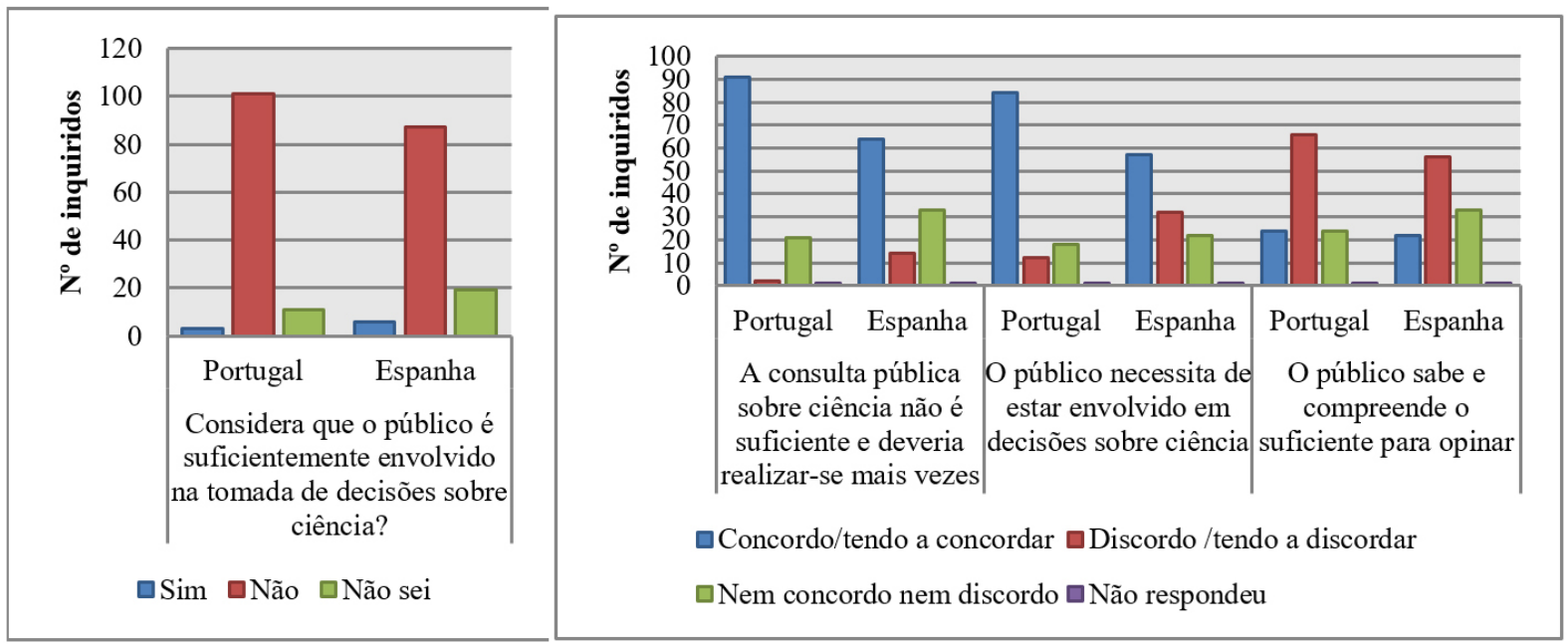

FIGURA 8 - Importância da consulta pública em temas de C\&T (1/2).

Os inquiridos também foram bastante expressivos quanto à sua concordância em relação à necessidade do público estar envolvido nas decisões sobre ciência, embora neste tópico os espanhóis se tenham mostrado um pouco mais divididos na resposta. É interessante verificar, no entanto, que embora tenha reconhecido essa necessidade de uma maior intervenção dos cidadãos, a maioria mostrou, ao mesmo tempo, não acreditar nas capacidades do público, discordando em relação ao público saber e compreender o suficiente para poder opinar.

Esta perceção negativa em relação ao poder dos cidadãos nas decisões refletiu-se nas respostas dos inquiridos em relação aos impactos da consulta pública e à importância da opinião do público face ao conhecimento científico (Figura 9). A maioria concordou que as consultas públicas não fazem diferença nas decisões políticas, que estas não são representativas da opinião do público e que as evidências científicas são mais importantes do que essa opinião, ainda que tenham referido que essas consultas não são um desperdício de dinheiro e de tempo. Esse descrédito é mais evidente nos cidadãos espanhóis, tendo-se mostrado mais divididos nas suas respostas do que os portugueses em relação à importância das evidências científicas face à opinião dos cidadãos e dos recursos utilizados na organização deste tipo de ações.

Portanto, ainda que a maioria tenha considerado que o público não é suficientemente envolvido na tomada de decisões sobre ciência, de concordar que é importante estar envolvido na consulta pública em ciência, ainda que não seja ativo a esse nível, uma percentagem relevante dos inquiridos, fundamentalmente espanhóis, mostrou não ter opinião formada acerca da importância da sua participação e da suficiência da sua intervenção. Estes dados podem denunciar alguma dificuldade por parte dos inquiridos em avaliar o grau do seu envolvimento e de perceber que influência podem ter os seus atos nas medidas tomadas pelos decisores, apesar da maioria ter assumido a sua incapacidade de influenciar o governo. Nota-se, portanto, um descrédito generalizado em relação ao seu poder no processo 


\section{Q8. Tendo em conta que "consulta pública" implica a consulta e audição de cidadãos sobre um}

determinado assunto, refira, por favor, se concorda ou discorda das seguintes afirmações?

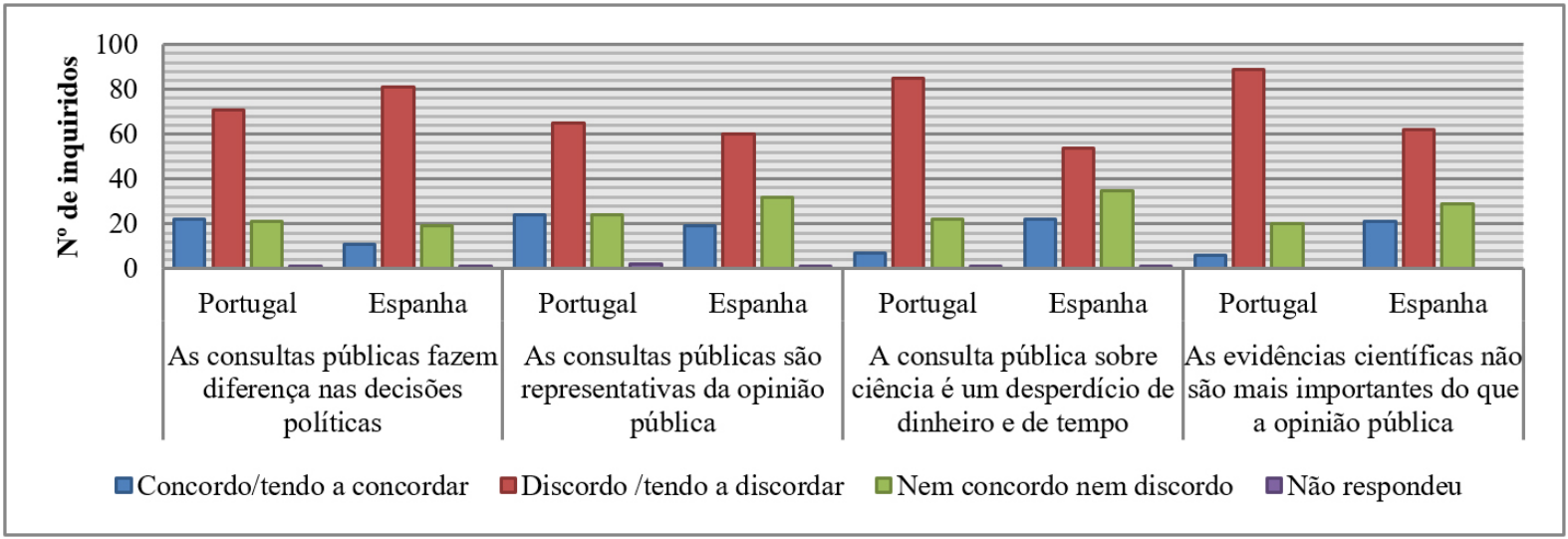

FIGURA 9 - Importância da consulta pública em temas de C\&T (2/2).

decisório, podendo ser um importante constrangimento na sua atuação cívica a este nível.

Por outro lado, esta inércia em relação à sua participação nestas temáticas pode ser explicada também pela perspetiva otimista que estes cidadãos demonstraram ter acerca dos benefícios da C\&T (Figura 10), concordando, aliás, com alguns dos dados apurados em estudos anteriores (Delicado \& Gonçalves, 2007; FECYT, 2011; 2015; European Commission, 2013).

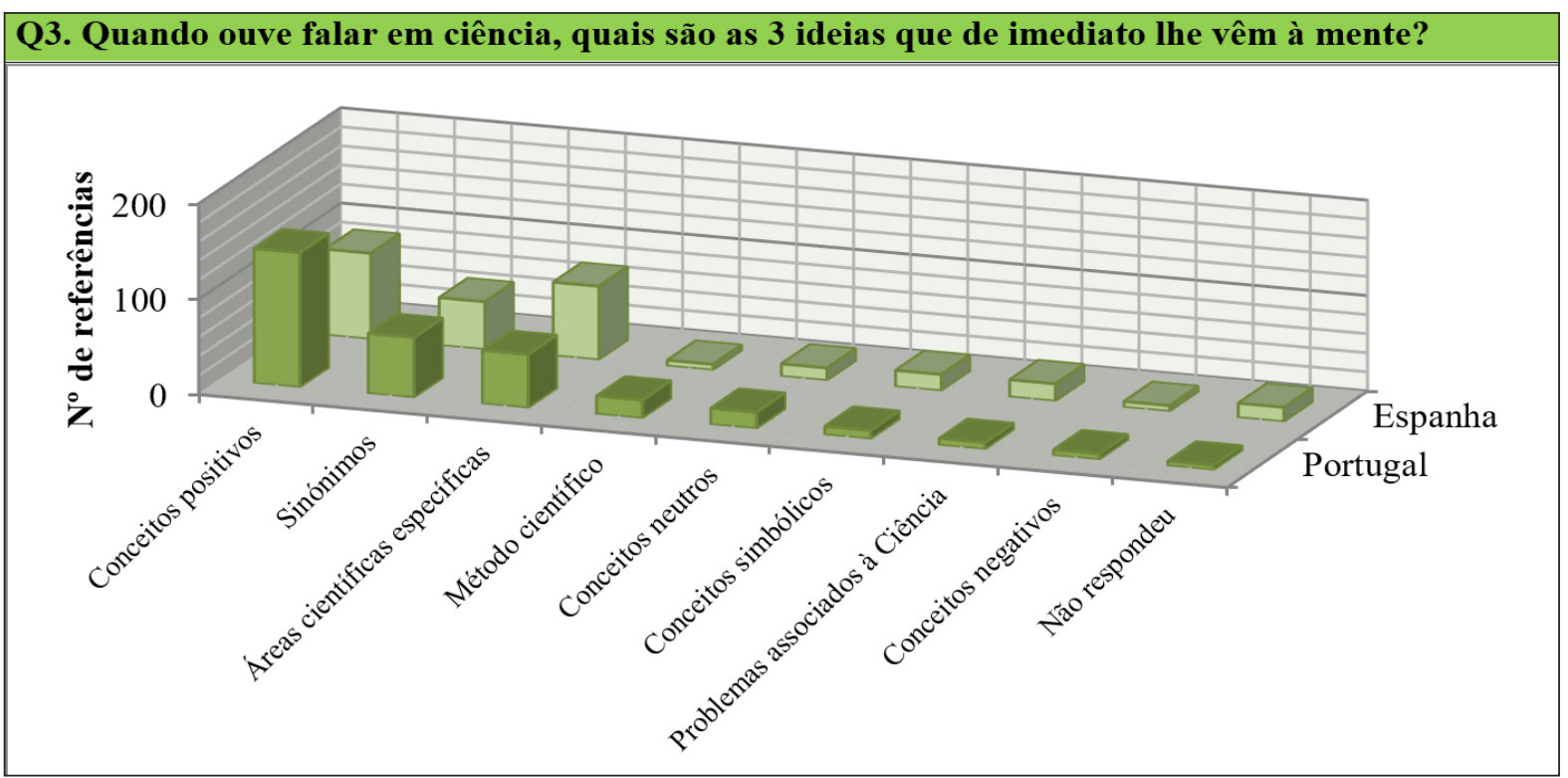

FIGURA 10 - Principais ideias associadas a ciência. 
É, porém, interessante notar que, apesar de se ter verificado uma tendência bastante otimista em relação à ciência no conjunto das ideias associadas pelos inquiridos na questão 3 do questionário, a questão 6 relativa à proposição "Os benefícios da ciência são sempre maiores do que qualquer efeito nocivo" deixa perceber que essa perceção positiva se esbate quando se colocam os benefícios e os riscos na balança (Figura 11). Ainda que no geral os indivíduos sondados se tenham mostrado um pouco divididos quanto à resposta, os portugueses mostraram-se mais pessimistas do que os espanhóis acerca dos impactos da ciência, discordando na sua maioria que os benefícios sejam sempre maiores do que os efeitos nocivos da ciência.

Outro aspeto que pode explicar este desinteresse na participação é a elevada confiança que os cidadãos de ambos os países demonstraram ter na comunidade científica e nas suas decisões. Tal como alguns estudos têm mostrado (Delicado \& Gonçalves, 2007; European Commission, 2010; 2013; Meira Cartea et al., 2011; 2013; Muñoz Van den Eynde, 2011; Revuelta, 2011; Bauer \& Howard, 2013; FECYT, 2015), também no questionário realizado os cientistas surgiram entre as fontes de informação que mais confiança inspiram nos cidadãos em questões de C\&T, ao lado das instituições científicas e dos livros (Figuras 12 e 13), em ambos os países.

Os participantes portugueses sondados reconheceram quase na sua totalidade a valiosa contribuição que os cientistas podem ter na melhoria das condições de vida, considerando que pensam nas consequências dos seus atos e anunciam as suas descobertas apenas depois de confirmadas pelos seus pares, ainda que para mais de metade dos inquiridos a sua independência seja posta em risco por causa de eventuais interesses económicos. Os espanhóis partilham o mesmo sentimento em relação aos contributos dos cientistas, mas mostraram-se mais divididos em relação ao facto dos cientistas pensarem nas consequências dos seus atos, tendo sido mais perentórios quanto ao ajustamento que fazem nos resultados obtidos e à incapacidade de resistirem a eventuais subornos que lhes tragam benefícios económicos. Os dados obtidos através do inquérito permitiram perceber, igualmente, que, de uma forma geral, a informação científica é assumida pelos cidadãos como credível.

Em termos de benefícios associados à participação dos cidadãos na tomada de decisões sobre ciência, as respostas dos inquiridos recolhidas através do inquérito não foram suficientemente expressivas, tendo em consideração que era uma

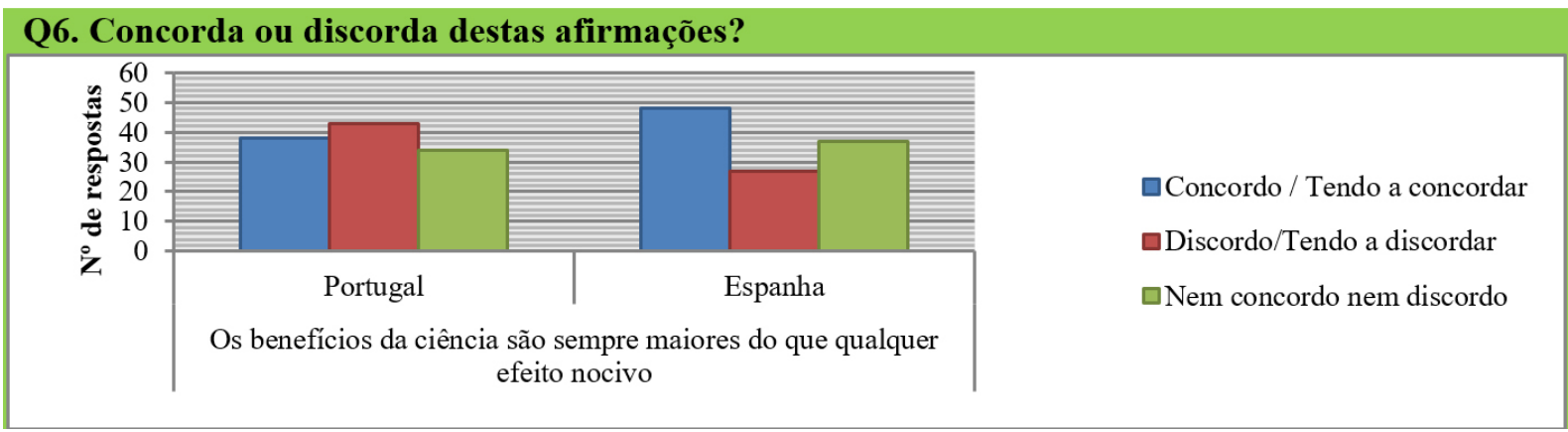

FIGURA 11 - Avaliação dos benefícios e riscos da ciência. 


\section{Q5. Que credibilidade atribui às seguintes fontes de informação?}

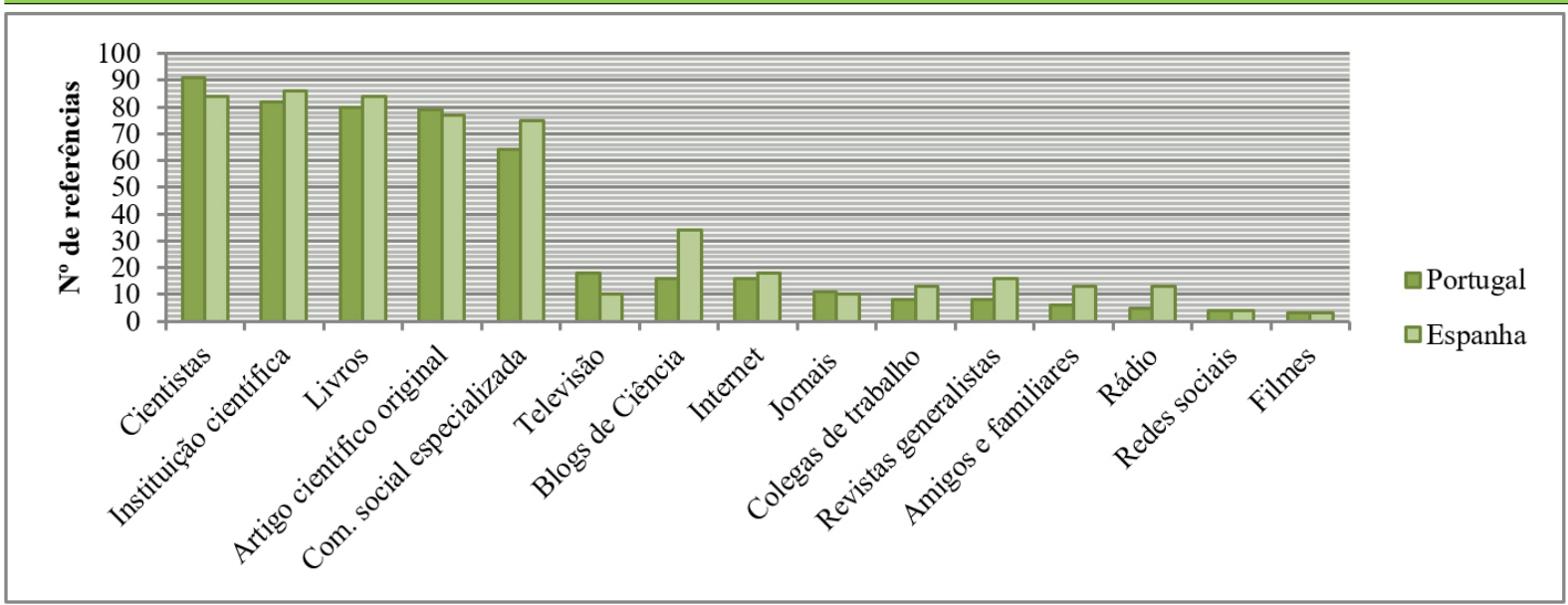

FIGURA 12 - Credibilidade das fontes de informação sobre C\&T.

\section{Q6. Concorda ou discorda destas afirmações?}

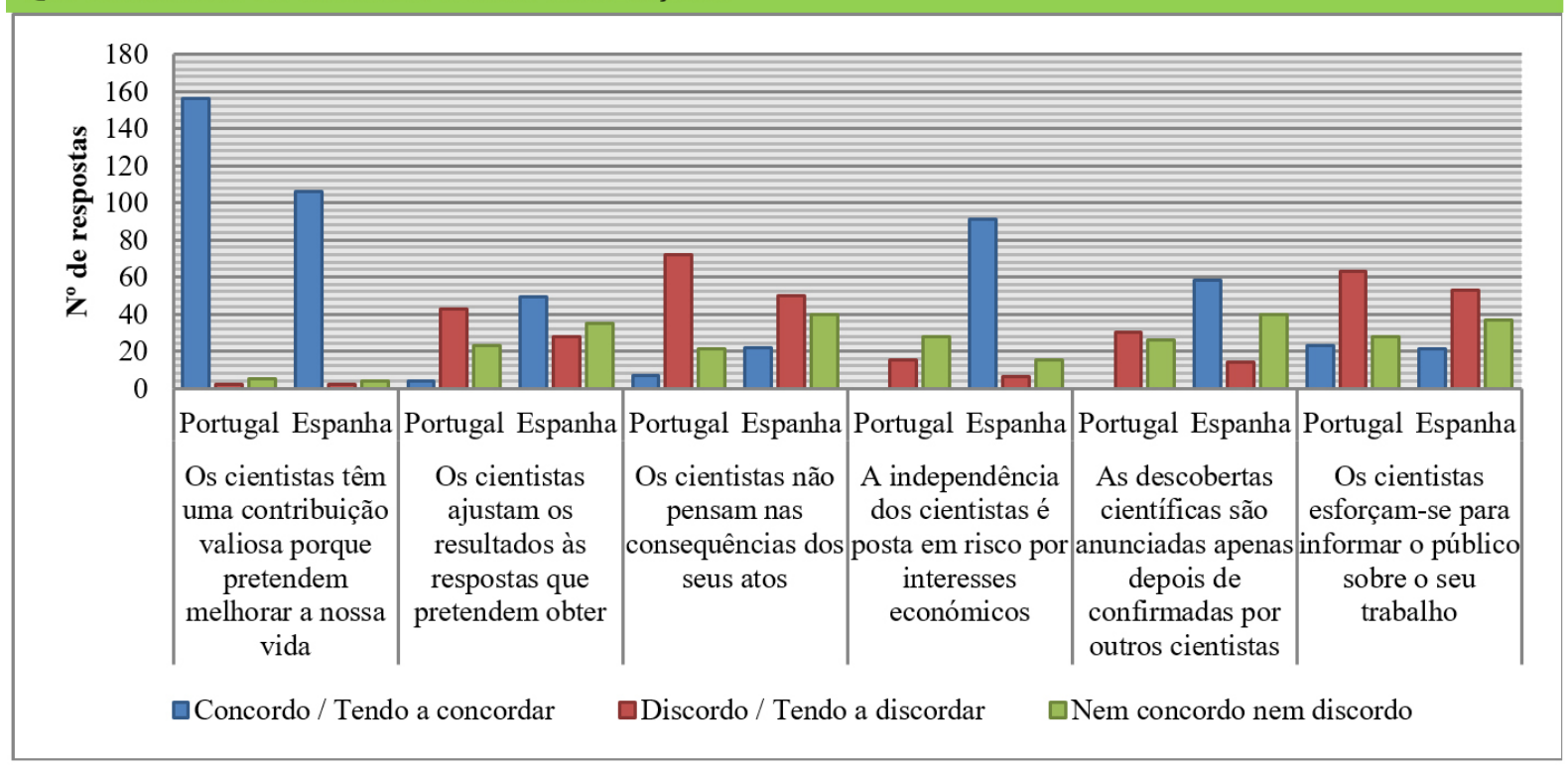

FIGURA 13 - Credibilidade dos cientistas.

resposta condicionada pela resposta à pergunta "o público é suficientemente envolvido na tomada de decisões sobre ciência?". A grande maioria respon- deu que não, sendo a taxa de resposta de apenas $2,66 \%$ nos inquiridos portugueses e de $5,34 \%$ nos inquiridos espanhóis. 


\subsection{Dificuldades sentidas no envolvimento}

Como já foi referido, a maioria dos inquiridos considerou que o público não participa o suficiente na tomada de decisões na área da ciência, tendo, portanto, indicado, conforme solicitava a questão, algumas barreiras que impedem esse envolvimento (Figura 14).

Através de uma pergunta fechada, a maioria dos indivíduos portugueses e espanhóis indicou a falta de conhecimentos do público e o desconhecimento do processo científico como principal constrangimento a uma participação cidadã mais regular.

Aliás, tal como alguns estudos têm vindo a mostrar (OCT, 1998; OCT, 2000; Miller et al., 2002; Gonçalves, 2003; Torres-Albero, 2005; Delicado \& Gonçalves, 2007; FECYT, 2011; 2015; Fundación
BBVA, 2011; Muñoz Van den Eynde 2011; Pavone et al., 2011; Revuelta, 2011; Revuelta \& Corchero, 2011), os dados obtidos no inquérito dão conta que a C\&T não é dos temas em que os portugueses e os espanhóis se sentem mais bem informados, ainda que surja entre os seis temas em que os portugueses se sentem muito bem ou bem informados e entre os oito apontados pelos espanhóis e que os temas que lideram a tabela em Portugal sejam de cariz eminentemente científico (saúde, ambiente e alterações climáticas).

O inquérito permitiu compreender, ainda, que o tema C\&T é muito amplo e vago para os inquiridos, uma vez que há uma grande disparidade entre o nível de informação do tema geral C\&T e de alguns temas iminentemente científicos mais específicos. Os espanhóis, ainda que com menos interesse, pa-

\section{Q7B. Assinale as principais barreiras a um maior envolvimento do público na tomada de decisões sobre ciência?}

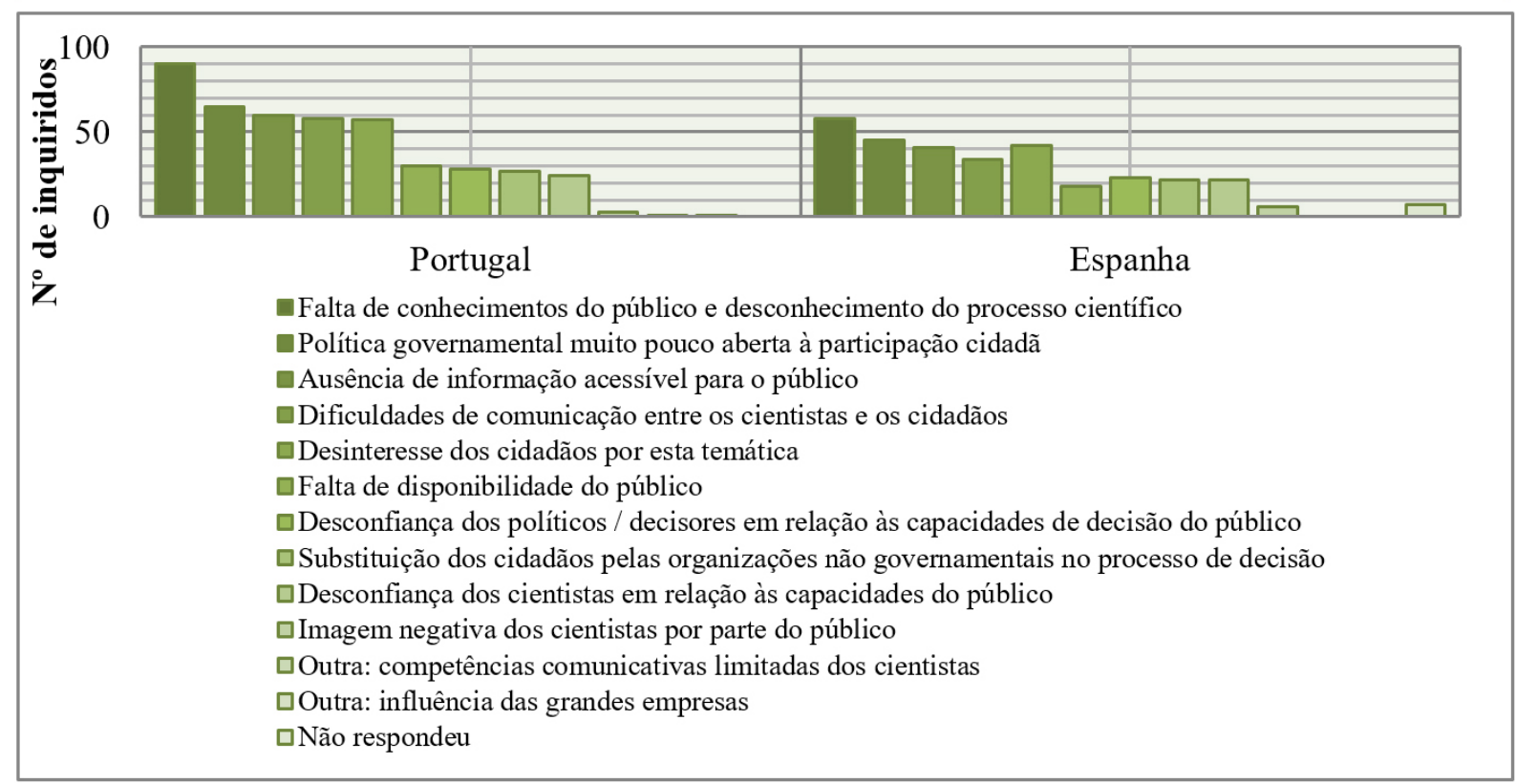

FIGURA 14 - Barreiras a um maior envolvimento do público na tomada de decisões sobre ciência. 
recem sentir-se, em média, mais informados sobre C\&T do que os portugueses.

Uma política governamental pouco aberta à participação cívica nas decisões, o difícil acesso à informação e problemas de comunicação entre os cientistas e os cidadãos foram outras barreiras consideradas importantes pelos inquiridos. Como vimos no gráfico 13, tanto os portugueses como os espanhóis concordaram em relação aos cientistas não se esforçarem o suficiente para informar o público sobre o seu trabalho.

Um importante constrangimento foi considerado, ainda, o desinteresse demonstrado pelos cidadãos por estas questões. Tal como estudos anteriores mostraram (OCT, 1998; 2000; Miller et al., 2002; Gonçalves, 2003; European Commission, 2005; 2010; 2013; FECYT, 2011; 2015; Torres-A1bero, 2005; Delicado \& Gonçalves, 2007; Cortassa, 2011; Fundación BBVA, 2011; Pavone et al., 2011; Revuelta, 2011; Bauer \& Howard, 2013) também este inquérito mostra que a C\&T não é dos temas com mais interesse para os portugueses e para os espanhóis.

\section{Considerações finais}

A participação dos cidadãos tem sido cada vez mais reconhecida na literatura como desejável para superar os desafios sociais e ambientais que a humanidade enfrenta e a necessidade de estimular esse envolvimento na mitigação e adaptação às alterações climáticas tem vindo a ser destacada em vários relatórios e acordos internacionais e defendida por vários autores (e.g. Callon, 1999; Irwin, 2006; Stirling, 2006; Wynne, 2006; Einsiedel, 2008; Delgado et al., 2011; Phillips et al., 2012; Rowe et al., 2010).

A maioria dos cidadãos continua, contudo, sem compreender a importância da questão, mantendo- -se afastada do problema, tornando-se necessário, portanto, perceber como é que se pode mobilizar os cidadãos para uma ação mais efetiva (Bord et al., 2000; Ockwell et al., 2009; Whitmarsh et al., 2013). Múltiplos estudos têm mostrado que a mudança de comportamento não está dependente apenas do nível de conhecimentos dos indivíduos e da sua compreensão. Os valores dos cidadãos; as suas condições económicas e sociais; as normas sociais; as estruturas que facilitam o seu envolvimento e a abertura das próprias instituições à participação dos cidadãos; a forma como a questão tem sido comunicada; e o contexto político parecem ser fatores importantes nessa mudança.

Esta investigação, pragmatizada com a administração de um inquérito a cidadãos portugueses e espanhóis, mostra que a maioria dos inquiridos têm muito interesse pelas alterações climáticas, de acordo com os relatórios já produzidos a este respeito (ex: Domínguez Arcos et al., 2011; Lázaro et al., 2011; Meira Cartea et al., 2011; 2013; European Commission, 2011a; 2011b; 2014a; Carvalho et al., 2014). Os efeitos e causas das alterações climáticas são os aspetos mais relevantes para os públicos, embora os efeitos se sobreponham às causas, como também já foi demonstrado anteriormente (ex: Carvalho, 2011b; Maria Cartea et al., 2013). Em ambos os países, a maioria referiu sentir-se razoavelmente informada acerca destes temas, embora os portugueses se sintam ligeiramente mais informados do que os espanhóis. A comunicação social, a internet e os livros são as fontes preferenciais da maioria destes cidadãos para se informarem sobre a questão.

$\mathrm{Na}$ sua grande maioria os cidadãos inquiridos reconheceram que têm um papel pouco participativo nas questões de C\&T, em particular na questão das alterações climáticas, admitindo que a sua intervenção deveria ser aprofundada. Existem, no entanto, alguns constrangimentos a contornar. Para 
além de se sentirem iletrados no que a temas de C\&T no geral diz respeito, os cidadãos apontaram como barreira importante a uma participação mais efetiva o facto dos decisores demostrarem alguma resistência em dialogar com eles e a implementar instrumentos participativos. O difícil acesso à informação foi apontado, igualmente, como um fator decisivo para o aprofundamento da participação pública na temática, bem como as dificuldades sentidas ao nível da comunicação entre os cientistas e os cidadãos e o desinteresse destes por temas relacionados com $\mathrm{C} \& \mathrm{~T}$.

Esta investigação permitiu-nos, portanto, perceber que os fatores que influenciam a participação dos portugueses e dos espanhóis em questões de C\&T, entre os quais se podem incluir o tema das alterações climáticas, parecem estar relacionados com o seu acesso ao processo de produção de conhecimento e/ou ao processo decisório, à falta de uma interação dialógica entre os vários atores e de integração dos vários tipos de saberes (Phillips et al., 2012) e, ainda, à representatividade dos atores envolvidos.

O acesso é dificultado pelo desinvestimento em mecanismos de participação pública por parte dos decisores e dos cientistas, colocando em risco também a interação, pela falta de cultura científica que os cidadãos inquiridos referiram sentir e pelo seu desinteresse por temas de C\&T. Essa iliteracia científica que apontam como possível barreira à participação pública e os problemas de comunicação existentes entre os cidadãos e os cientistas dificultam uma possível aprendizagem mútua. Os inquiridos colocam ainda em causa a representatividade nos processos, considerando que nem todos podem participar porque não estão interessados ou não estão devidamente informados.

Esta investigação mostra, ainda, que, apesar dos entrevistados identificarem os benefícios da sua participação e de reconhecerem que o público não é suficientemente envolvido na tomada de decisões sobre ciência, uma percentagem relevante não tem opinião formada acerca da importância da sua participação e da suficiência da sua intervenção, denunciando um descrédito generalizado em relação ao seu poder no processo decisório. Esta forma de se ver no processo pode ser um importante constrangimento na atuação cívica a este nível.

Portanto, desde logo há aqui um desafio a ultrapassar. Mais do que reunir condições e criar oportunidades de participação, há que fazer perceber aos cidadãos a importância dos seus contributos e as potencialidades que uma aprendizagem mútua, a partilha de conhecimentos individuais, perspetivas, valores culturais, sociais e éticos pode significar, atribuindo-lhes uma maior responsabilização na investigação e na gestão deste tipo de problemáticas. No fundo, sensibilizar os cidadãos, "educar para a participação" e incrementar hábitos de cidadania científica (Mejlgaard, 2009) e ambiental, no caso das alterações climáticas (eg: Eden, 1996; Heras, 2002; Ockwell et al., 2009; Wesselink et al., 2011; Phillips et al., 2012; Carr et al., 2013). Este pode ser uma intervenção de significativa importância, uma vez que é essencial para a democratização da C\&T que o cidadão se reconheça como um "cidadão científico" (Sturgis, 2014).

Apesar da sua pertinência, devem ser reconhecidas algumas limitações ao estudo aqui apresentado. Este estudo foi desenvolvido no âmbito de uma investigação mais abrangente e que permitiu, numa segunda fase, contrastar os dados aqui obtidos com recurso a outros métodos. A aplicação de um questionário permite a realização de um estudo mais extensivo do que outros métodos, potencia a comparação com outros estudos do mesmo teor e a análise de correlações entre variáveis, entre outros aspetos. No entanto, tem, também, desvantagens. Os 
resultados dependem muito da motivação e honestidade dos inquiridos, sendo que os constrangimentos de tempo e outros associados ao preenchimento de um questionário podem introduzir algumas distorções nas respostas. A validade das conclusões de um estudo por questionário depende, também, da natureza da amostra. Neste caso específico, tratou-se de um questionário de caráter exploratório, e, ainda que tenha reunido dados respeitantes a pessoas com diferentes perfis, deve recordar-se que as amostragens acidentais não têm uma natureza probabilística e, como tal, os resultados não podem ser generalizados à população. As amostras inquiridas neste estudo apresentam, manifestamente, caraterísticas que não correspondem à população geral, como é o caso da distribuição de habilitações e profissões. Deve ainda ser referido que, por razões de espaço, neste artigo não se comparou os dois grupos sociais

\section{Referências}

Almeida, J. F. de (Ed.). Os portugueses e o ambiente: I. Inquérito às representações e práticas dos portugueses sobre o ambiente. Oeiras: Celta Editora, 2000.

Almeida, J. F. de (Ed.). Os portugueses e o ambiente: II. Inquérito nacional às representações e práticas dos portugueses sobre o ambiente. Oeiras: Celta Editora, 2004.

Alonso, L. E.; Fernández Rodríguez, C. J.; Ibáñez Rojo, R. Crisis y nuevos patrones de consumo: discursos sociales acerca del consumo ecológico en el ámbito de las grandes ciudades españolas. EMPIRIA. Revista de Metodología de Ciencias Sociales, 29, 13-38, 2014. doi: DOI/empiria.29.2014.12939

AXA. La Percepción Individual de los Riesgos Climáticos. Spain. 2013. Disponível em: <https://www.axa.es/ Seguros/imagenes/ENCUESTA\%20PERCEPCION\%20 CAMBIO\%20CLIMATICO_tcm5-11048.pdf $>$.

Azevedo, J.; Aires, L.; Couto, A. I. Os processos de mediação de ciência em televisão: efeitos sobre a sua eficácia inquiridos (cidadãos indiscriminados e participantes de iniciativas de divulgação científica) mas que se registaram algumas diferenças interessantes entre ambos.

Não obstante as limitações apontadas, o questionário aplicado cumpriu o objetivo de lançar pistas para a investigação posterior, sugerindo um conjunto de questões com interesse. Num momento posterior, procurou-se aprofundar os resultados com a realização de grupos focais, que permitiram analisar as interações grupais, facilitando a compreensão do processo de construção das perceções, atitudes e representações sociais (Kitzinger, 1994; Morgan, 1997; Krueger \& Casey, 2009), e promovendo a autorreflexão. À data de redação deste artigo, estavam em preparação outras publicações que permitirão a divulgação dessas conclusões.

comunicativa. Prisma.COM, (1), 43-60, 2005. Disponível em: <http://revistas.ua.pt/index.php/prismacom/article/ view/585>.

Bauer, M. W.; Howard, S. The Culture of Science in Modern Spain: An Analysis of Public Attitudes across Time, Age Cohorts and Regions. Spain. 2013. Disponível em: <http:// eprints.1se.ac.uk/50349/>.

Bickerstaff, K.; Lorenzoni, I.; Jones, M.; Pidgeon, N. Locating Scientific Citizenship: The Institutional Contexts and Cultures of Public Engagement. Science, Technology \& Human Values, 35(4), 474-500, 2010. doi: $10.1177 / 0162243909345835$

Bord, R. J.; O'Connor, R. E.; Fisher, A. In What Sense Does the Public Need to Understand Global Climate Change? Public Understanding of Science, 9(3), 205-218, 2000. doi: 10.1088/0963-6625/9/3/301

Cabecinhas, R.; Carvalho, A.; Lázaro, A. Representações sociais sobre alterações climáticas. In: Carvalho, A. (Ed.). 
As alterações climáticas, os media e os cidadãos. Braga: Grácio Editor, 2011. p. 177-194.

Callon, M. The Role of Lay People in the Production and Dissemination of Scientific Knowledge. Science, Technology \& Society, 4(1), 81-94, 1999. doi: 10.1177/097172189900400106

Capstick, S. Public Understanding of Climate Change as a Social Dilemma. Sustainability, 5(8), 3484-3501, 2013. doi: 10.3390/su5083484

Caride, J. A.; Meira, P. A. Educação ambiental e desenvolvimento humano. Lisboa: Instituto Piaget.2004.

Carr, W. A.; Preston, C. J.; Yung, L.; Szerszynski, B.; Keith, D. W.; Mercer, A. M. Public Engagement on Solar Radiation Management and Why it Needs to Happen Now. Climatic Change, 121, 567-577, 2013. doi: 10.1007/s10584-0130763-y

Carvalho, A. The Challenges of Communicating Climate Change. In: Carvalho, A. (Ed.). Communicating Climate Change: Discourses, Mediations and Perceptions. Braga: Centro de Estudos de Comunicação e Sociedade (CECS) da Universidade do Minho, 2008a. p. 8-11.

Carvalho, A. (Ed.). Communicating Climate Change: Discourses, Mediations and Perceptions. Braga: Centro de Estudos de Comunicação e Sociedade (CECS) da Universidade do Minho, 2008b.

Carvalho, A. Conclusões. In: Carvalho, A. (Ed.). As alterações climáticas, os media e os cidadãos. Coimbra: Grácio Editor, 2011a. p. 223-240.

Carvalho, A. (Ed.). As alterações climáticas, os media e os cidadãos. Braga: Grácio Editor, 2011b.

Carvalho, A.; Gupta, J. State Commitment to Promoting Public Participation. The UNFCCC and Citizens' Roles in Climate Change Politics. In: Carvalho, A.; Peterson, T. R. (Eds.). Climate Change Politics: Communication and Public Engagement. EUA: Cambria Press, 2012. p. 123-161.

Carvalho, A.; Peterson, T. R. (Eds.). Climate Change Politics: Communication and Public Engagement. EUA: Cambria Press, 2012.

Carvalho, A.; Schmidt, L.; Santos, F. D.; Delicado, A. Climate Change Research and Policy in Portugal. Wiley Interdisciplinary Reviews: Climate Change, 5(2), 199-217, 2014. doi: $10.1002 /$ wcc. 258
CIS. Ecología y Medio Ambiente (III). Estudio n ${ }^{\circ}$ 2682. Madrid, 2007. Disponível em: $<$ http://www.cis.es/cis/opencm/ ES/1_encuestas/estudios/ver.jsp?estudio=8160>.

Cortassa, C. Credibilidade y Confianza en Actores, Instituciones y Fuentes de Información sobre Ciencia y Tecnología. In: Anais del V Encuesta de Percepción Social de la Ciencia y la Tecnología. Madrid, Espanha: Fundación Española para la Ciencia y la Tecnología (FECYT), 2011. p. 47-66.

Delgado, A.; Kjølberg, K. L.; Wickson, F. Public Engagement Coming of Age: From Theory to Practice in STS Encounters With Nanotechnology. Public Understanding of Science, 20(6), 826-845, 2011. doi: 10.1177/0963662510363054

Delicado, A.; Gonçalves, M. E. Os portugueses e os novos riscos: resultados de um inquérito. Análise Social, XLII(184), 687-718, 2007. Disponível em: <http://observa. iscte.pt/v2/docs/03\%20Relatorio\%20Inquirito.pdf $>$.

Delicado, A.; Pato, J.; Schmidt, L. As alterações climáticas e a opinião pública - Portugal e Europa em perspectiva. Paper apresentado no Colóquio As Alterações Climáticas nos Media e na Opinião Pública. Lisboa. 2011.

Domínguez Arcos, F.; Labandeira Villot, X.; Loureiro García, M. Políticas contra el Cambio Climático y Preferencias Sociales en Galicia y España. Revista Galega de Economía, 20(1), 33-51, 2011.

Doyle, J. Mediating Climate Change UK: Ashgate.2011

Dunlap, R. E. Lay Perceptions of Global Risk: Public Views of Global Warming in Cross-National Context. International Sociology, 13(4), 473-498, 1998. doi: $10.1177 / 026858098013004004$

Eden, S. Public Participation in Environmental Policy: Considering Scientific, Counter-Scientific and Non-Scientific Contributions. Public Understanding of Science, 5(3), 183-204, 1996. doi: 10.1088/0963-6625/5/3/001

Einsiedel, E. F. Public Participation and Dialogue. In: Bucchi, M.; Trench, B. (Eds.). Handbook of Public Communication and Science and Technology. London: Routledge,2008. p. 173-184.

Emmert, S.; Van De Lindt, M.; Luiten, H. Bar Energy. Barriers to Changes in Energy Behaviour among End Consumers and Households. Brussels, 2010. Disponível em: <http://www.barenergy.eu/uploads/media/Barenergy_FinalReport_screen.pdf $>$. 
European Commission. Europeans, Science \& Technology: Report. Special Eurobarometer 224/Wave EB 63.1. Brussels, 2005. Disponível em: <http://ec.europa.eu/public_opinion/archives/ebs/ebs_224_report_en.pdf $>$.

European Commission. Science and technology: Report. Special Eurobarometer 340/Wave EB 73.1. Brussels, 2010. Disponível em: $<$ http://ec.europa.eu/public_opinion/archives/eb_special_359_340_en.htm>.

European Commission. Attitudes of European Citizens Towards the Environment: Report. Special Eurobarometer 365/Wave EB 75.2. Brussels, 2011a. Disponível em: <http://ec.europa.eu/public_opinion/archives/ebs/ ebs_365_sum_en.pdf $>$.

European Commission. Climate Change: Report. Special Eurobarometer 372/Wave EB 75.4. Brussels, 2011b. Disponível em: $<$ http://ec.europa.eu/public_opinion/archives/ ebs/ebs_372_en.pdf>.

European Commission. EUR 25251 - Monitoring Policy and Research Activities on Science in Society in Europe (MASIS). Final synthesis report. Luxemburgo, 2012. Disponível em: <http://ec.europa.eu/research/science-society/ document_library/pdf_06/monitoring-policy-research-activities-on-sis_en.pdf $>$.

European Commission. Responsible Research and Innovation (RRI), Science and Technology: Report. Special Eurobarometer 401 / Wave EB79.2. Brussels, 2013. Disponível em: $<$ http://ec.europa.eu/public_opinion/archives/ ebs/ebs_401_en.pdf $>$.

European Commission. Climate Change: Report. Special Eurobarometer 409 / Wave EB 80.2. Brussels, 2014a. Disponível em: $<$ http://ec.europa.eu/public_opinion/archives/ ebs/ebs_409_en.pdf>.

European Commission. Public Perceptions of Science, Research and Innovation: Report. Special Eurobarometer 419 / Wave EB81.5. Brussels, 2014b. Disponível em: <http://ec.europa.eu/public_opinion/archives/ebs/ ebs_419_en.pdf $>$.

European Institute for Public Participation. Public Participation in Europe. An International Perspective. Germany, 2009. Disponível em: <http://www.participationinstitute. org/wp-content/uploads/2009/06/pp_in_e_report_03_06. pdf $>$.
FECYT. V Encuesta de Percepción Social de la Ciencia y la Tecnología. Madrid, Espanha, 2011. Disponível em: <http:// icono.publicaciones.fecyt.es/05\%29Publi/AA\%29Percepcion/pdf/Publicacion_PSC2010.pdf>.

FECYT. VII Encuesta de Percepción Social de la Ciencia. Spain, 2015. Disponível em: http://www.idi.mineco.gob. es/stfls/MICINN/Prensa/NOTAS_PRENSA/2015/Dossier_PSC_2015.pdf

Ferreira, V. O inquérito por questionário. In: Silva, A. S. P.; Porto, J. M. (Ed.)._Metodologia das Ciências Sociais. Porto: Afrontamento, 2001. p. 165-196.

Fundación BBVA. Percepción y Actitudes de los Españoles hacia el Calentamiento Global. Madrid, 2008. Disponível em: $<$ http://www.fbbva.es/TLFU/dat/presentacion_calentamiento_global.pdf $>$.

Fundación BBVA. Estudio Internacional de Cultura Cientifica. Madrid, Espanha, 2011. Disponível em: <http:// www.madrimasd.org/cienciaysociedad/documentos/doc/ Cultura_cientifica_BBVA_08-05-2012.pdf $>$.

Gonçalves, M. E. (Ed.). Os portugueses e a ciência. Lisboa: D. Quixote, 2003.

Heras, F. Entre Tantos - Guía práctica para dinamizar procesos participativos sobre problemas ambientales y sostenibilidad. Valladolid: Gea, 2002.

Hulme, M. Why We Disagree About Climate Change: Understanding Controversy, Inaction and Opportunity. Cambridge: Cambridge University Press, 2009.

IPCC. Climate Change 2007. Synthesis Report. Contribution of Working Groups I, II and III to the Fourth Assessment Report of the Intergovernmental Panel on Climate Change. Geneva, Switzerland, 2007. Disponível em: $<$ http://www. ipcc.ch/publications_and_data/publications_and_data_reports.shtml\#.UQ_S7_Kwbcw>.

IPCC. Climate Change 2013. The Physical Science Basis. Working Group I Contribution to the Fifth Assessment Report of the Intergovernmental Panel on Climate Change. Cambridge, United Kingdom, New York, 2013.

IPCC. Climate Change 2014: Impacts, Adaptation, and Vulnerability. Working Group II Contribution to the Fifth Assessment Report of the Intergovernmental Panel on Climate Change. Cambridge, United Kingdom, New York, 2014a. Disponível em: <http://www.ipcc.ch/report/ar5/wg2/>. 
IPCC. Climate Change 2014: Mitigation of Climate Change. Working Group III Contribution to the Fifth Assessment Report of the Intergovernmental Panel on Climate Change. Cambridge, United Kingdom, New York, 2014b. Disponível em: <http://www.ipcc.ch/report/ar5/wg3/>.

Irwin, A. The Politics of Talk: Coming to Terms with the "New" Scientific Governance. Social Studies of Science, 36(2), 299-320, 2006. doi: 10.1177/0306312706053350

Irwin, T. Implications for Climate-Change Policy of Research on Cooperation in Social Dilemmas; Background Paper to the 2010 World Development Report (Policy Research Working Paper 5006). Washington, DC, 2009. doi: 10.1596/1813-9450-5006

Jori García, G. El Cambio Climático como Problema y el Diálogo Social como Solución. Investigaciones Geográficas, 48, 125-160, 2009. doi: 10.14198/INGEO2009.48.05

Kitzinger, J. The Methodology of Focus Groups: The Importance of Interaction Between Research Participants. Sociology of Health and Illness, 16(1), 103-121, 1994. doi: 10.1111/1467-9566.ep11347023

Krueger, R. A.; Casey, M. A. Focus Groups: A Practical Guide for Applied Research. Thousand Oaks, CA: Sage Publications, 2009.

Lakoff, G. Why it Matters How We Frame the Environment. Environmental Communication: A Journal of Nature and Culture, 4(1), 70-81, 2010. doi: 10.1080/17524030903529749

Lázaro, A.; Cabecinhas, R.; Carvalho, A. Uso dos media e envolvimento com as alterações climáticas. In: Carvalho, A. (Ed.). As alterações climáticas, os media e os cidadãos. Braga: Grácio Editor, 2011. p. 195-222.

Lorenzoni, I.; Leiserowitz, A.; De Franca Doria, M.; Poortinga, W.; Pidgeon, N. F. Cross-National Comparisons of Image Associations with "Global Warming" and "Climate Change" Among Laypeople in the United States of America and Great Britain. Journal of Risk Research, 9(3), 265-281, 2006. doi: 10.1080/13669870600613658

Lorenzoni, I.; Nicholson-Cole, S.; Whitmarsh, L. Barriers Perceived to Engaging with Climate Change Among the UK Public and their Policy Implications. Global Environmental Change, 17(3-4), 445-459, 2007. doi: 10.1016/j. gloenvcha.2007.01.004
Martins, C. Manual de análise de dados quantitativos com recursos ao IBM SPSS. Braga: Psiquilíbrios Edições, 2011.

Meira Cartea, P. Á. Comunicar el Cambio Climático. Escenario social y líneas de actuación. Spain: Ministerio de Medio Ambiente y Medio Rural y Marino - Organismo Autónomo de Parques Nacionales, 2008.

Meira Cartea, P. Á.; Arto Blanco, M.; Heras Hernández, F.; Iglesias da Cunha, L.; Lorenzo Castiñeiras, J. J.; Montero Souto, P. La Respuesta de la Sociedad Española ante el Cambio Climático 2013. Spain: Fundación MAPFRE, Instituto de Prevención Salud y Medio Ambiente, 2013.

Meira Cartea, P. Á.; Arto Blanco, M.; Heras Hernández, F.; Montero Souto, P. La Sociedad ante el Cambio Climático. Conocimientos, Valoraciones y Comportamientos en la Población Española 2011. Spain: Fundación MAPFRE, Instituto de Prevención Salud y Medio Ambiente, 2011.

Meira Cartea, P. Á.; Arto Blanco, M.; Montero Souto, P. La Sociedad ante el Cambio Climático. Conocimientos, Valoraciones y Comportamientos en la Población Española 2009. Spain: Fundación MAPFRE, Instituto de Prevención Salud y Medio Ambiente, 2009.

Mejlgaard, N. The Trajectory of Scientific Citizenship in Denmark: Changing Balances between Public Competence and Public Participation. Science and Public Policy, 36(6), 483-496, 2009. doi: 10.3152/030234209X460962

Miller, S.; Caro, P.; Koulaidis, V.; Semir, V.; Staveloz, W.; Vargas, R. Report from the Expert Group-Benchmarking the Promotion of RTD Culture and Public Understanding of Science. Brussels, 2002. Disponível em: $<\mathrm{ftp}: / / \mathrm{ftp}$.cordis. europa.eu/pub/era/docs/bench_pus_0702.pdf $>$.

Morgan, D. Focus Group As Qualitative Research. Qualitative Research Methods. London: Sage Publications, 1997.

Moser, S. C. Communicating Climate Change: History, Challenges, Process and Future Directions. Wiley Interdisciplinary Reviews-Climate Change, 1(1), 31-53, 2010. doi: 10.1002/Wcc.011

Muñoz Van den Eynde, A. Evolución de la Percepción Social de la Ciencia y la Tecnología en España en el Periodo 20022010. In: V Encuesta de Percepción Social de la Ciencia y la Tecnología. Madrid, Espanha: Fundación Española para la Ciencia y la Tecnología (FECYT), 2011. p. 239-260. 
O’Neill, S.; Nicholson-Cole, S. "Fear Won't Do It": Promoting Positive Engagement With Climate Change Through Visual and Iconic Representations. Science Communication, 30(3), 355-379, 2009. doi: 10.1177/1075547008329201

Ockwell, D.; Whitmarsh, L.; O’Neill, S. Reorienting Climate Change Communication for Effective Mitigation: Forcing People to be Green or Fostering Grass-Roots Engagement? Science Communication, 30(3), 305-327, 2009. doi: $10.1177 / 1075547008328969$

OCT. Inquérito à cultura científica dos portugueses. Lisboa, 1998.

OCT. Inquérito à cultura científica dos portugueses. Lisboa, 2000.

Oltra, C.; Sala, R.; Gamero, N.; Solà, R. Cambio Climático y Opinión Pública en España. Percepción del Problema y Política Energética. Sistema, Revista de Ciencias Sociales, 2005, 93-106, 2008.

Owens, S. Commentary: 'Engaging the Public': Information and Deliberation in Environmental Policy. Environment and Planning A, 32, 1141-1148, 2000. doi: 10.1068/a3330

Pavone, V.; Osuna, C.; Degli Esposti, S. Invertir en Ciencia y Tecnología en Tiempos de Austeridad Económica: ¿Qué Opinan los Ciudadanos? In: V Encuesta de Percepción Social de la Ciencia y la Tecnología. Madrid, Espanha: Fundación Española para la Ciencia y la Tecnología (FECYT), 2011. p. 115-136.

Pereira, A. Guia prático da utilização do SPSS: análise de dados para Ciências Sociais e Psicologia. Lisboa: Edições Sílabo, 2006.

Phillips, L.; Carvalho, A.; Doyle, J. (Eds.). Citizen Voices. Performing Public Participation in Science and Environment Communication. Bristol, UK, Chicago, USA: Intellect, 2012.

Raihani, N.; Aitken, D. Uncertainty, Rationality and Cooperation in the Context of Climate Change. Climatic Change, 108(1-2), 47-55, 2011. doi: 10.1007/s10584-010-0014-4

Revuelta, G. DG Research Monitoring Policy and Research Activities on Science in Society in Europe (MASIS) National Report, Spain. Luxemburgo, 2011. Disponível em: <http:// www.masis.eu/files/reports/MASIS_SPAIN_report.pdf $>$.

Revuelta, G.; Corchero, C. Búsqueda Activa y Recepción Pasiva de Información Sobre Ciencia y Tecnología. In: $V$
Encuesta de Percepción Social de la Ciencia y la Tecnología. Madrid, Espanha: Fundación Española para la Ciencia y la Tecnología (FECYT), 2011. p. 153-202.

Rodriguez-Priego, N.; Montoro Ríos, F. J.; Ibanez Zapata, J. A. Mapping Environmental Behaviour in the Spanish Context. The International Journal of Environmental Sustainability, 8(3), 37-46, 2012.

Rowe, G.; Rawsthorne, D.; Scarpello, T.; Dainty, J. R. Public Engagement in Research Funding: a Study of Public Capabilities and Engagement Methodology. Public Understanding of Science, 19(2), 225-239, 2010. doi: $10.1177 / 0963662508096780$

Schmidt, L.; Delicado, A. Alterações climáticas na opinião pública. In: Schmidt, L.; Delicado, A. (Eds.). Ambiente, alterações climáticas, alimentação e energia: a opinião dos portugueses. Lisboa: Imprensa de Ciências Sociais, 2014. p. 113-143.

Schmidt, L; Delicado, A.; Ferreira, J. G.; Fonseca, S.; Seixas, J.; Sousa, D.; Valente, S. O ambiente em 25 anos de Eurobarómetro. Lisboa: Observa, 2011.

Schmidt, L.; Nave, J. G. (Eds.). As alterações climáticas no quotidiano: estudo comportamental de curta duração Relatório final. Lisboa: Instituto Superior de Ciências do Trabalho e da Empresa, 2003.

Solaun, K.; Gómez, I.; Sopelana, A.; Pérez, M.; Ares, Z.; Urban, J. La Gestión del Cambio Climático en España 2014. Spain, 2014. Disponível em: $<$ http://www.factorco2. com/comun/docs/147-La\%20gesti\%F3n\%20del\%20cambio $\% 20$ clim $\%$ E1tico $\% 20$ en $\% 20$ Espa $\%$ F1a $\% 202014 \_\% 20$ Factor\%20CO2.pdf $>$.

Stirling, A. (Ed.). From Science and Society to Science in Society: Towards a Framework for 'Co-Operative Research'. Report of a European Commission Workshop Governance and Scientific Advice Unit of DG RTD, Directorate C2. Brussels: Directorate General Research and Technology Development, 2006.

Sturgis, P. On the Limits of Public Engagement for the Governance of Emerging Technologies. Public Understanding of Science, 23(1), 38-42, 2014. doi: $10.1177 / 0963662512468657$

Todt, O. Social Decision Making on Technology and the Environment in Spain. Technology in Society, 21(2), 201216, 1999. doi: 10.1016/S0160-791X(99)00006-8 
Torres-Albero, C. La Ambivalencia Ante la Ciencia y la Tecnología. Revista Internacional de Sociología, 42, 9-38, 2005. doi: 10.3989/ris.2005.i42.195

Wesselink, A.; Paavola, J.; Fritsch, O.; Renn, O. Rationales for Public Participation in Environmental Policy and Governance: Practitioners' Perspectives. Environment and Planning A, 43(11), 2688-2704, 2011. doi: 10.1068/a44161

Whitmarsh, L.; O’Neill, S.; Lorenzoni, I. Public Engagement with Climate Change: What do we Know and Where do we Go from Here? International Journal of Media \& Cultural Politics, 9(1), 7-25, 2013. doi: 10.1386/macp.9.1.7_1

Wynne, B. Public Engagement as a Means of Restoring Public Trust in Science - Hitting the Notes, but Missing the Music? Community Genetics, 9(3), 211-220, 2006. doi: $10.1159 / 000092659$

Yábar Sterling, A. Mecanismos de Consulta, Participación y Cooperación para una Estrategia Española de Cambio Climático.M+A Revista Electrónic@de Medioambiente, 2, 1-16, 2006. 